\title{
Stopping eye and hand movements: Are the processes independent?
}

\author{
Leanne Boucher, Veit STUPhorn, Gordon D. Logan, \\ JefFrey D. SChall, ANd Thomas J. Palmeri \\ Vanderbilt University, Nashville, Tennessee
}

\begin{abstract}
To explore how eye and hand movements are controlled in a stop task, we introduced effector uncertainty by instructing subjects to initiate and occasionally inhibit eye, hand, or eye + hand movements in response to a color-coded foveal or tone-coded auditory stop signal. Regardless of stop signal modality, stop signal reaction time was shorter for eye movements than for hand movements, but notably did not vary with knowledge about which movement to cancel. Most errors on eye + hand stopping trials were combined eye + hand movements. The probability and latency of signal respond eye and hand movements corresponded to predictions of Logan and Cowan's (1984) race model applied to each effector independently.
\end{abstract}

Many studies have detailed the linkage between movements fof the eyes and hands. Reaction times (RTs) of eyes and hands covary under various circumstances (Biguer, Jeannerod \& Prablanc, 1982; Fischer \& Rogal, 1986; Fisk \& Goodale, 1985; Gielen, van den Heuvel, \& van Gisbergen, 1984; Gribble, Everling, Ford \& Mattar, 2002; Herman, Herman, \& Maulucci, 1981; Hodgson, Muller, \& O’Leary, 1995; Lunenburger \& Hoffmann, 2003; Lunenburger, Kutz, \& Hoffmann, 2000; Neggers \& Bekkering, 2000; Sailer, Eggert, Ditterich, \& Straube 2000). Even saccade dynamics can be affected by limb kinetics (van Donkelaar, Siu, \& Walterschied, 2004; Snyder, Calton, Dickinson, \& Lawrence, 2002; Tipper, Howard, \& Paul, 2001). For example, movements of the eyes and hands to opposite locations are delayed relative to movements to the same location (Fisk \& Goodale, 1985), and saccades are produced with shorter reaction times when produced with an arm movement (Lunenburger et al., 2000; Snyder et al., 2002). Further, saccades directed away from the endpoint of a pointing movement are delayed until the end of the arm movement (Neggers \& Bekkering, 2000). Neurophysiological evidence has suggested a linkage as well. In particular, neural activity in the superior colliculus associated with saccade production is modulated by limb position (Stuphorn, Hoffmann, \& Miller, 1999), and neural activity in posterior parietal cortex associated with limb movements is modulated by eye position (Snyder, 2000). Overall, the data have been interpreted to indicate a general facilitation of coordinated movements of eyes with hands.

Another critical aspect of motor control is the withholding of a movement, for control over movements is the hallmark of voluntary behavior. This ability can be probed by the countermanding, or stop signal, task. This is an RT task where an imperative stop signal is infrequently presented which instructs subjects to cancel the planned movement (Hanes \& Schall, 1995; Lappin \& Erikson, 1966; Logan, 1994). Logan and Cowan (1984) showed that performance on this task could be accounted for by a race between stochastic processes that generate (GO process) or inhibit (STOP process) the movement. This race model predicts the probability and latency of errors of commission and provides an estimate of stop signal reaction time (SSRT), the time needed to cancel the planned movement.

A previous study found that saccadic eye movements stop sooner than hand movements but did not examine the coordination of stopping between the eyes and hands (Logan \& Irwin, 2000). Here we ask, given the evidence that the eyes and hand move together, do they stop together? Specifically, are partially prepared eye and hand movements inhibited independently or together? We measured performance in both blocked and interleaved trials in which subjects were instructed to make an eye movement alone, a hand movement alone, or a combined eye + hand movement toward an eccentric target. On a minority of trials, subjects had to cancel their previously planned eye movement, hand movement, or coordinated eye + hand movement if a stop signal occurred. In the blocked condition, subjects knew in advance which effector (eye, hand, eye + hand) to stop; in the interleaved condition, subjects were cued by the color of a visual stop signal (Experiment 1) or the tone of an acoustic stop signal (Experiment 2) which effector to stop.

The eye-only and hand-only conditions were included for comparison to previous findings (Logan \& Irwin, 2000) and to provide estimates of baseline performance of each effector in the coordinated eye + hand condition. The eye + hand condition tested the degree to which stop-

G. D. Logan, gordon.logan@vanderbilt.edu 


\section{No Stop Signal Trials}

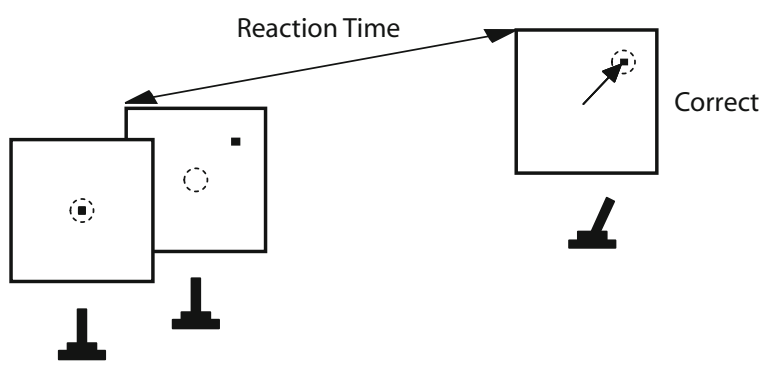

Stop Signal Trials

Signal Inhibit

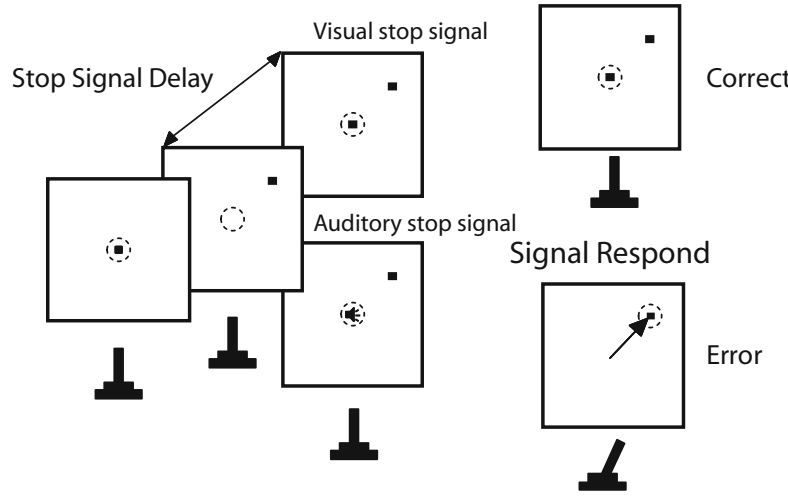

Figure 1. Countermanding task. After subjects grasped a joystick in central position and fixated a central spot, the central spot was replaced by a visual target in one of the four cardinal locations. Subjects either made a saccade, rotated a joystick, or produced both movements toward the target depending on the condition. On infrequent, random trials a stop signal was presented. The stop signal was either the reappearance of the fixation spot (Experiment 1) or a brief auditory stimulus (Experiment 2). The color of the fixation spot or the tone of the auditory stimulus cued subjects to inhibit either their eye movement, their hand movement, or the combined eye + hand movement.

ping is coordinated between effectors. Independent control of eye and hand movements would result in separate inhibition of eye or hand movements. Coordinated control of eye and hand movements would prevent stopping one effector without stopping the other. Dependency between the two effector systems would result in less inhibition of one effector if the other moves.

\section{METHOD}

\section{Subjects}

Five naive subjects participated in Experiment 1 (visual stop signal) and three naive subjects participated in Experiment 2 (auditory stop signal). All subjects were paid for their time. Each subject participated in a minimum of 8 (maximum of 11) sessions. All subjects reported having normal or corrected-to-normal vision. Informed consent was obtained before the experiment began. The experimental procedure was approved by the Vanderbilt University Institutional Review Board.

\section{Apparatus and Stimuli}

In both experiments, eye position was monitored through pupil tracking using the EyeLink II eye tracker (SR Research, Canada) at a sampling rate of $250 \mathrm{~Hz}$ with average gaze position error $<0.5^{\circ}$, noise limited to $<0.01^{\circ} \mathrm{RMS}$. Saccades were detected on-line using a velocity criterion $\left(35^{\circ} / \mathrm{sec}\right)$. Hand movements were monitored using a Microsoft SideWinder joystick. All analyses were performed off-line. Subjects were seated $57 \mathrm{~cm}$ from the computer monitor which delivered the visual stimuli with their head in a chinrest. The fixation and targets subtended $1.0^{\circ}$ and were light gray $\left(34 \mathrm{~cd} / \mathrm{m}^{2}\right)$ on a darker gray $\left(18 \mathrm{~cd} / \mathrm{m}^{2}\right)$ background. In Experiment 1, the stop signal was a color-coded visual target that subtended $1.0^{\circ}$ and were either blue $\left(34 \mathrm{~cd} / \mathrm{m}^{2}\right)$, yellow $\left(34 \mathrm{~cd} / \mathrm{m}^{2}\right)$, or red $\left(34 \mathrm{~cd} / \mathrm{m}^{2}\right)$ and remained on until the end of the trial. In Experiment 2, the stop signal was an auditory target that differed in tone and was 500,1250 , or $2000 \mathrm{~Hz}$ and lasted $100 \mathrm{msec}$ in duration (60dB).

\section{Procedure}

Subjects performed the countermanding, or stop signal, task (Hanes \& Schall, 1995; Hanes \& Carpenter, 1995; Logan \& Irwin, $2000)$ in both experiments. Seventy percent of the trials were no stop signal trials. These required the subject to maintain central gaze on the fixation spot until it disappeared (after a uniformly random delay of 500-1000 msec) and an eccentric target appeared at one of 4 randomly selected locations (upper left, upper right, lower left, lower right) equidistant $\left(8.5^{\circ}\right)$ from the central fixation spot (Figure 1). Subjects were instructed to respond as quickly as possible to the appearance of the target. The remaining $30 \%$ of trials were stop signal trials. On these trials, the fixation spot re-illuminated after a variable delay, called stop signal delay (SSD), cuing subjects that the response they were SSD to make needed to be inhibited. The SSDs were 25 , $75,125,175,225$, or $275 \mathrm{msec}$; each delay occurred with equal probability. Stop signal trials were labeled signal inhibit or signal respond (also referred to as canceled or noncanceled, respectively) based on whether subjects inhibited or did not inhibit the planned movement, respectively. Subjects were told at the start of each block of 120 trials whether they had to make an eye movement, a hand movement, or a combined eye + hand movement in response to the target. The stop signal differed in color (Experiment 1) or differed in tone (Experiment 2) to indicate which effector needed to be inhibited; the mapping of color or tone onto which effector to stop (eye, hand, eye + hand) was randomly assigned for each subject. In the eye only condition, subjects gripped the joystick but never moved it while shifting gaze to the target; only the eye stop signal was presented. In the hand only condition, subjects maintained central gaze while moving the joystick toward the target position; only the hand stop signal was presented. There were two types of eye + hand conditions in which both the eye and the hand moved toward the target. In the blocked eye + hand condition, only eye + hand stop signal was presented indicating that both the eye + hand movement needed to be inhibited. In the

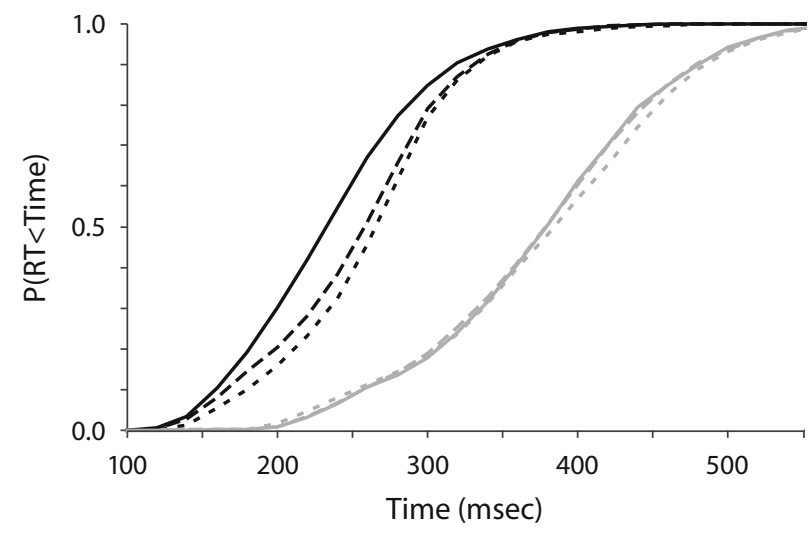

Figure 2. Cumulative distributions of reaction times on no stop signal trials in Experiment 1 for eye (black) and hand (gray) movements in the eye or hand only (solid line), blocked eye + hand (dashed line), or interleaved eye + hand (dotted line) conditions. 
Table 1

Mean No Stop Signal Reaction Times (in Milliseconds) in Experiment 1

\begin{tabular}{lccccccc}
\hline & \multicolumn{3}{c}{ Eye } & & \multicolumn{3}{c}{ Hand } \\
\cline { 2 - 3 } \multicolumn{1}{c}{ Subject } & Eye Only & $\begin{array}{c}\text { Blocked } \\
\text { Eye + Hand }\end{array}$ & $\begin{array}{c}\text { Interleaved } \\
\text { Eye + Hand }\end{array}$ & & Hand Only & $\begin{array}{c}\text { Blocked } \\
\text { Eye + Hand }\end{array}$ & $\begin{array}{c}\text { Interleaved } \\
\text { Eye + Hand }\end{array}$ \\
\hline S.N. & 270 & 295 & 298 & & 383 & 372 & 376 \\
J.B. & 251 & 281 & 283 & & 392 & 392 & 388 \\
K.W. & 249 & 250 & 268 & & 440 & 440 & 448 \\
E.F. & 276 & 288 & 288 & & 451 & 465 & 476 \\
E.L. & 232 & 256 & 273 & & 287 & 287 & 285 \\
Grand mean & 255 & 274 & 282 & & 391 & 391 & 394 \\
\hline
\end{tabular}

interleaved eye + hand condition, either the eye, hand, or eye + hand stop signal was presented in an unpredictable, interleaved manner with equal probability (i.e., each stop signal occurred on $10 \%$ of the trials) and subjects had to inhibit the appropriate effector. There was no cursor displayed that served as feedback to subjects as to where they were responding. Each session included all 4 blocks, the order of which was counterbalanced across sessions for each subject.

Behavioral performance was evaluated through measurements of saccadic and manual RTs on no stop signal trials, RTs on trials in which a response was made in spite of the stop signal (signal re-
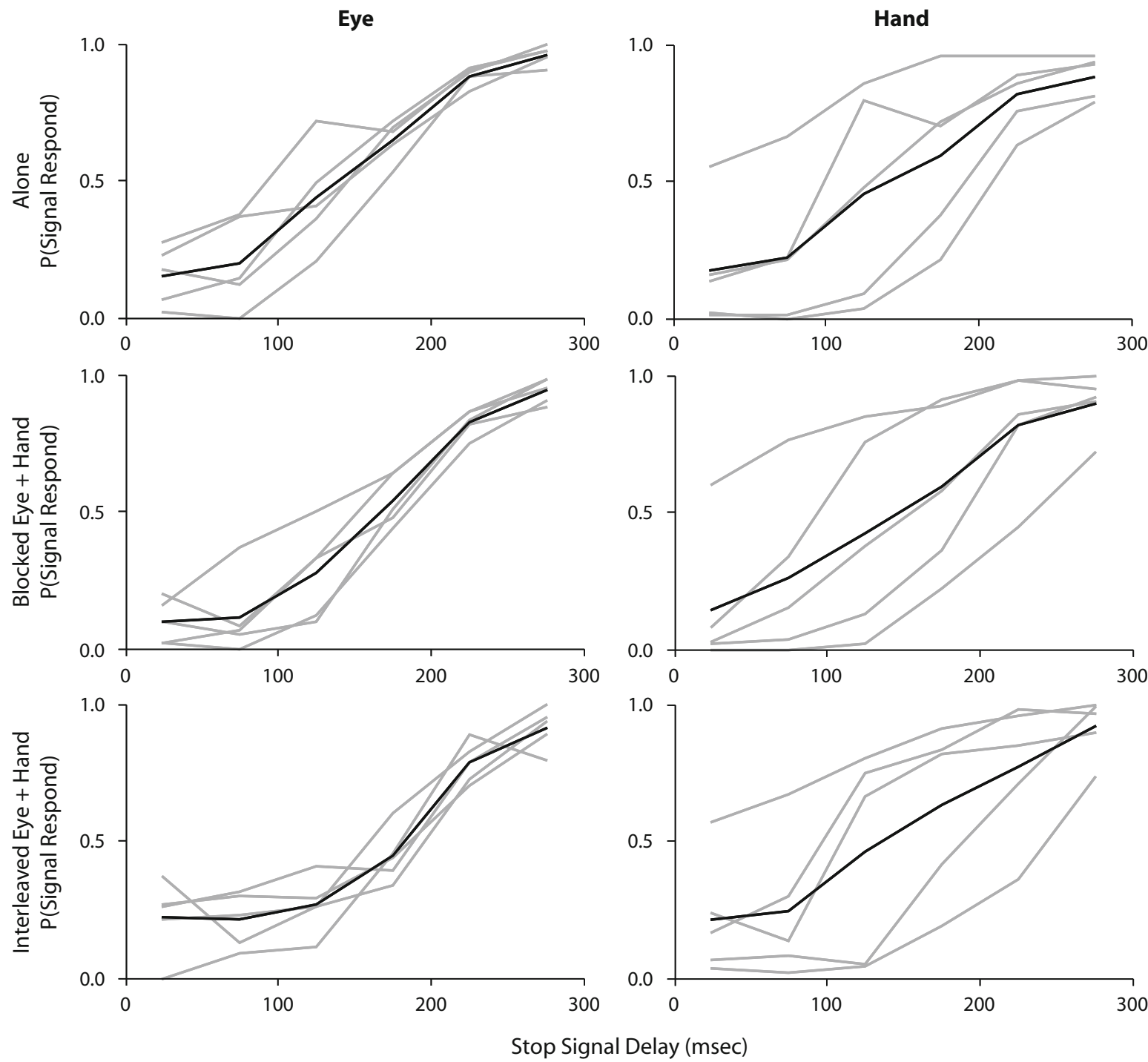

Figure 3. Proportion of signal respond trials as a function of stop signal delay with a foveal visual stop signal (Experiment 1) Inhibition functions for the eye and hand are in the left and right columns, respectively. Different rows display the inhibition functions in the either effector alone (top row), blocked eye + hand (middle row), or interleaved eye + hand (bottom row) conditions. Black line is the average inhibition function across subjects (gray lines). 
Table 2

Probability of Not Canceling an Eye Movement at Each Stop Signal Delay (SSD) in Experiment 1

\begin{tabular}{|c|c|c|c|c|c|c|}
\hline \multirow[b]{2}{*}{ Subject } & \multicolumn{6}{|c|}{ SSD } \\
\hline & 25 & 75 & 125 & 175 & 225 & 275 \\
\hline \multicolumn{7}{|c|}{ Eye-Only Condition } \\
\hline S.N. & .23 & .37 & .41 & .63 & .82 & .95 \\
\hline J.B. & .17 & .12 & .36 & .69 & .89 & 1.00 \\
\hline K.W. & .06 & .14 & .49 & .72 & .91 & .97 \\
\hline E.F. & .02 & .00 & .20 & .53 & .88 & .90 \\
\hline E.L. & .28 & .38 & .72 & .68 & .90 & .98 \\
\hline Grand mean & .15 & .20 & .44 & .65 & .88 & .96 \\
\hline \multicolumn{7}{|c|}{ Blocked Eye + Hand Condition } \\
\hline S.N. & .20 & .08 & .33 & .48 & .82 & .88 \\
\hline J.B. & .10 & .05 & .10 & .51 & .84 & .98 \\
\hline K.W. & .02 & .06 & .33 & .64 & .86 & .95 \\
\hline E.F. & .02 & .00 & .12 & .44 & .74 & .90 \\
\hline E..L & .16 & .37 & .50 & .64 & .87 & .98 \\
\hline Grand mean & .10 & .11 & .28 & .54 & .83 & .94 \\
\hline \multicolumn{7}{|c|}{ Interleaved Eye + Hand Condition } \\
\hline S.N. & .26 & .31 & .40 & .39 & .79 & .95 \\
\hline J.B. & .00 & .09 & .11 & .45 & .88 & .79 \\
\hline K.W. & .37 & .13 & .26 & .60 & .83 & 1.00 \\
\hline E.F. & .26 & .30 & .29 & .44 & .70 & .88 \\
\hline E.L. & .21 & .23 & .26 & .34 & .73 & .94 \\
\hline Grand mean & .22 & .21 & .27 & .44 & .79 & .91 \\
\hline
\end{tabular}

spond trials), and the probability of not canceling each effector as a function of stop signal delay (the inhibition function). As mentioned previously, performance in the stop signal task can be accounted for through a race model (Logan \& Cowan 1984). This model provides an estimate of the time needed to respond to the stop signal and cancel the movement, the stop signal reaction time (SSRT). With the integration method, the finish time of the STOP process is assumed to be constant. Although surely not so, violations of this assumption have little effect on the validity of this estimate of SSRT (Band, van der Molen, \& Logan, 2003; DeJong, Coles, Logan, \& Gratton, 1990; Logan \& Cowan, 1984). For each stop signal delay, SSRT is defined as the RT at which the integral of the no stop signal RT distribution equals the proportion of signal respond trials at that stop signal delay minus the stop signal delay. With the difference method, the finish time of the STOP process is assumed to be a random variable. The probability of responding given a stop signal at a given delay is described by the inhibition function. The difference method treats the inhibition function as a cumulative distribution. Mathematical analysis shows that the mean of this distribution equals the mean of the finish time for the GO process minus SSRT. Consequently, mean SSRT can be calculated by subtracting the mean of the inhibition function from the mean RT on no stop signal trials. Because there is no a priori reason to favor the SSRT derived from one method over that from the other, and because the difference in the values calculated by the two methods is typically small, an overall SSRT estimate was taken as the average of the SSRT calculated from both methods.

\section{RESULTS}

\section{Experiment 1: Visual Stop Signal}

In this experiment, subjects participated in a stop signal task with a color coded stop signal. Subjects were instructed to move their eyes, hand, or both their eyes and hand in response to a peripheral target unless an infrequent stop signal was presented. On these trials, the color of the stop signal instructed subjects whether they had to inhibit either their eye movement, hand movement, or combined eye + hand movement. Trials were blocked such that subjects either knew or did not know in advance which effector to inhibit. One purpose of this study was to determine what effect effector uncertainty had on stopping behavior. A second purpose of the study was to determine whether the GO and STOP processes for the eyes and hands, which are the theoretical constructs of initiating and inhibiting movements, interact within and/or across effectors.

No stop signal performance. The saccadic and manual RTs produced on no stop signal trials in all conditions are shown in Figure 2 as cumulative distribution functions combined across subjects; individual subject mean RTs are given in Table 1 . We performed a 2 (eye, hand) $\times 3$ (condition: alone, blocked, interleaved) ANOVA on the mean RTs. As shown previously, saccades had shorter RTs than hand movements $\left[F(1,4)=17.95, M S_{\mathrm{e}}=1.11 \times 10^{5}\right.$, $p=.01]$. Also, a main effect of condition was observed $\left[F(2,8)=22.50, M S_{\mathrm{e}}=586, p<.01\right]$, and the interaction between effector and condition was significant $[F(2,8)=$ $\left.4.38, M S_{\mathrm{e}}=366, p=.05\right]$. We explored this interaction by performing a simple main effect analysis for condition on the hand and eye RTs and found no effect of condition on hand RTs $\left[F(1,4)=0.40, M S_{\mathrm{e}}=21, p=.68\right]$, but a significant effect on eye RTs $\left[F(1,4)=16.18, M S_{\mathrm{e}}=\right.$ $931, p<.01]$. Thus, eye movements were sensitive to the condition manipulation, but hand movements were not. In particular, eye movement RTs were the shortest in the eye only condition $\left[F(1,4)=22.14, M S_{\mathrm{e}}=1702, p<.01\right]$, with the blocked and interleaved conditions yielding longer RTs $\left[F(1,4)=4.19, M S_{\mathrm{e}}=160, p=.11\right]$ that were indistinguishable from each other. Thus, as observed pre-

Table 3

Probability of Not Canceling a Hand Movement at Each Stop Signal Delay (SSD) in Experiment 1

\begin{tabular}{lcccccr}
\hline & \multicolumn{5}{c}{ SSD } \\
\cline { 2 - 7 } \multicolumn{1}{c}{ Subject } & 25 & 75 & 125 & 175 & 225 & 275 \\
\hline \multicolumn{5}{c}{ Hand-Only Condition } \\
S.N. & .13 & .22 & .79 & .70 & .89 & .92 \\
J.B. & .16 & .21 & .48 & .72 & .86 & .93 \\
K.W. & .02 & .02 & .09 & .38 & .75 & .81 \\
E.F. & .02 & .00 & .04 & .22 & .63 & .78 \\
E.L. & .56 & .67 & .86 & .95 & .95 & .96 \\
Grand mean & .18 & .22 & .45 & .59 & .82 & .88 \\
& Blocked Eye + Hand Condition & & \\
S.N. & .08 & .34 & .76 & .91 & .98 & .95 \\
J.B. & .03 & .15 & .38 & .58 & .86 & .90 \\
K.W. & .02 & .03 & .13 & .36 & .82 & .92 \\
E.F. & .00 & .00 & .02 & .22 & .45 & .72 \\
E.L. & .60 & .77 & .85 & .89 & .98 & 1.00 \\
Grand mean & .14 & .26 & .43 & .59 & .82 & .90 \\
& Interleaved Eye + Hand Condition & & \\
S.N. & .17 & .30 & .75 & .84 & .98 & .97 \\
J.B. & .24 & .14 & .67 & .82 & .85 & .90 \\
K.W. & .06 & .08 & .05 & .41 & .71 & .98 \\
E.F. & .04 & .02 & .04 & .19 & .36 & .73 \\
E.L. & .57 & .67 & .80 & .91 & .95 & 1.00 \\
Grand mean & .22 & .24 & .46 & .63 & .77 & .92 \\
\hline
\end{tabular}




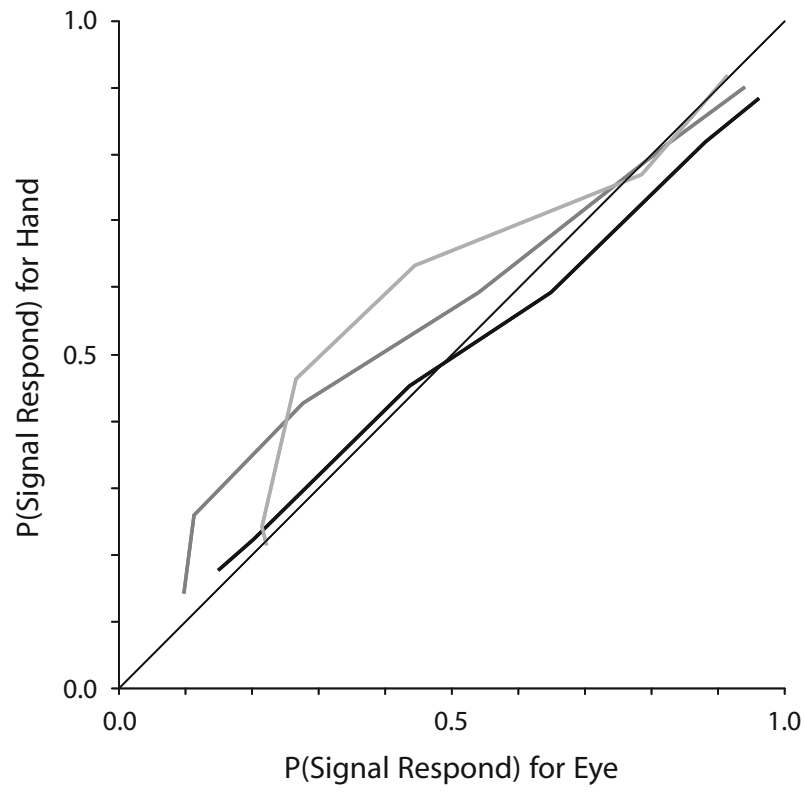

Figure 4. Proportion of signal respond trials for the eye versus the hand in the alone (black line), blocked eye + hand (dark gray line) and interleaved eye + hand (light gray line) conditions with a visual stop signal (Experiment 1). Stop signal delay is implied. The 1:1 line is also plotted.

viously, shifting gaze while directing the hand requires a longer RT than simply shifting gaze alone.

Stop signal performance. Figure 3 plots the probability of failing to cancel a movement as a function of stop signal delay (called the inhibition function) for all subjects for each stopping condition; Tables 2 and 3 provide values for individual subjects for saccadic and manual performance, respectively. In the interleaved condition, we included all failures to cancel a movement, regardless of which effector the stop signal instructed to inhibit. We consider the inhibition functions as a function of stop signal type in a later analysis. We performed a 2 (effector) $\times 3$ (condition: alone, blocked, interleaved) $\times 6$ (stop signal delay) ANOVA on the inhibition functions. Typical individual idiosyncrasies do not obscure the oft-observed increase in the probability of signal respond trials with longer stop signal delays. This finding is supported by a significant main effect of $\operatorname{SSD}\left[F(5,20)=70.56, M S_{\mathrm{e}}=\right.$ $2.92, p<.01]$. No significant main effects of effector $\left[F(1,4)=0.15, M S_{\mathrm{e}}=0.05, p=.72\right]$ or condition
$\left[F(2,8)=2.16, M S_{\mathrm{e}}=0.03, p=.18\right]$ were observed. This can be seen in Figure 4, which plots the proportion of signal respond trials for eye versus hand movements. All conditions fall along the 1:1 line, although there was a trend for eye movements to be inhibited more often at the intermediate stop signal delays. The only significant twoway interaction was between condition and stop signal delay $\left[F(10,40)=2.27, M S_{\mathrm{e}}=0.01, p=.03\right]$.

Race model analysis. The race model explains countermanding performance in terms of independent, stochastic finish times of GO and STOP processes responsible for movement initiation and inhibition, respectively (Logan \& Cowan, 1984). The race model assumes that the GO process is activated on all trials and that the STOP process is activated whenever that response needs to be inhibited. A response is made if and when the GO process finishes before the STOP process. The response is withheld if the STOP process finishes before the GO process. The finish time of the GO process corresponds to the RTs on no stop signal and on signal respond trials. The finish time of the covert STOP process cannot be observed, but application of the race model affords the determination of SSRT derived from the no stop signal RT distribution and the inhibition function.

Table 4 presents the SSRT for each condition and each effector for each subject. We performed a 2 (effector) $\times 3$ (condition: alone, blocked, interleaved) ANOVA on the SSRTs. In response to the foveal visual stop signal, SSRT for eye movements was shorter than that for hand movements by about $150 \mathrm{msec}[F(1,4)=682.02$, $\left.M S_{\mathrm{e}}=1.48 \times 10^{5}, p<.01\right]$. Notably, uncertainty about which effector to cancel had no effect on SSRT $[F(2,8)=$ $\left.0.11, M S_{\mathrm{e}}=20.02, p=.90\right]$. Also, the interaction of effector and condition was not significant $[F(2,8)=1.46$, $\left.M S_{\mathrm{e}}=88.17, p=.29\right]$. Thus, surprisingly, it took the same amount of time to inhibit a movement whether or not subjects knew in advance which effector to inhibit.

The independence of the finish times of the GO and STOP processes has been well documented with a single effector (i.e., Band et al., 2003; Boucher, Logan, Palmeri, Schall, 2007; Logan \& Cowan, 1984). The present data address the question of whether the STOP processes for different effectors interact. As a first step in answering this question, we examined the relationship between the $\mathrm{GO}$ processes for the eyes and hands. In accordance with previous reports, we found a correlation between the RTs of eye and hand movements in no stop signal trials in both

Table 4

Mean of Stop Signal Reaction Times (in Milliseconds) in Experiment 1

\begin{tabular}{lccccccc}
\hline & \multicolumn{3}{c}{ Eye } & & \multicolumn{3}{c}{ Hand } \\
\cline { 2 - 3 } \multicolumn{1}{c}{ Subject } & Eye Only & $\begin{array}{c}\text { Blocked } \\
\text { Eye + Hand }\end{array}$ & $\begin{array}{c}\text { Interleaved } \\
\text { Eye + Hand }\end{array}$ & & Hand Only & $\begin{array}{c}\text { Blocked } \\
\text { Eye + Hand }\end{array}$ & $\begin{array}{c}\text { Interleaved } \\
\text { Eye + Hand }\end{array}$ \\
\hline S.N. & 120 & 130 & 123 & & 270 & 270 & 268 \\
J.B. & 115 & 114 & 105 & & 252 & 240 & 260 \\
K.W. & 115 & 98 & 120 & & 258 & 260 & 269 \\
E.F. & 111 & 109 & 111 & & 252 & 249 & 267 \\
E.L. & 108 & 119 & 89 & & 211 & 250 & 216 \\
Grand mean & 114 & 114 & 110 & & 248 & 254 & 256 \\
\hline
\end{tabular}



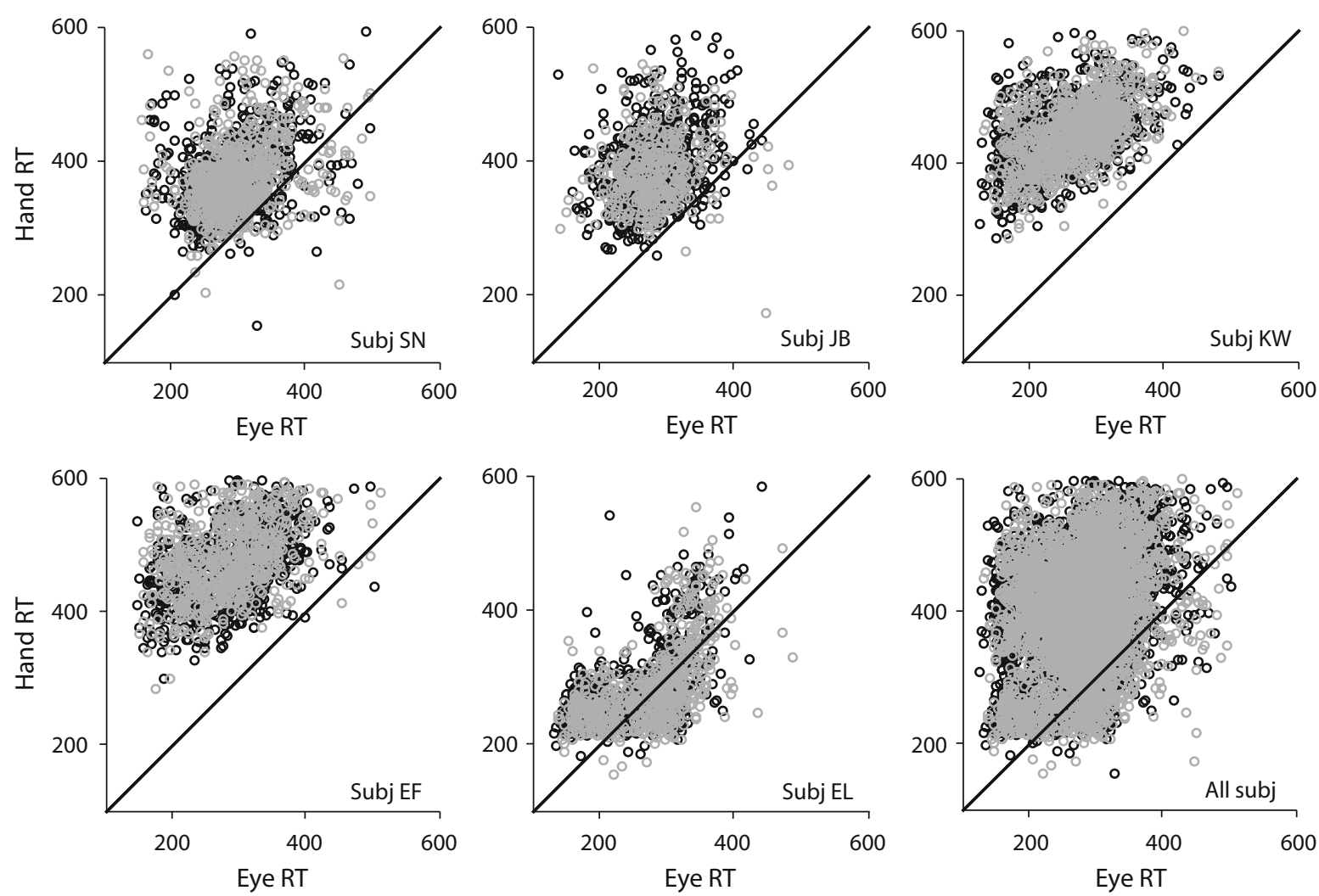

Figure 5. Eye versus hand RTs on no stop signal trials in the blocked (black) and interleaved (gray) eye + hand conditions for individual and all subjects with a visual stop signal (Experiment 1).

the blocked and interleaved eye + hand conditions (Figure 5, Table 5). The eyes moved sooner than the hand on the majority of trials for each subject. Correlations between the eye and hand RTs were significant (all $p \mathrm{~s}<.01$ ) and ranged between .34 and .56 in the blocked eye + hand condition (mean $=.43$ ) and between .16 and .57 (mean $=$ .39 ) in the interleaved eye + hand condition. In addition, the degree of correlation within subjects was consistent across conditions.

A correlation between saccade and hand RT can occur through an interaction between the effector systems or through the influence of another factor, such as arousal, affecting the speed of each process while preserving stochastic independence. Therefore, another means of investigating whether there is an interaction between the GO and STOP processes for the eye and hand is through an analysis of how the STOP processes of the eye and hand interact with one another. In particular, will a failure to inhibit one effector oblige a failure to inhibit the other effector?

According to Logan and Cowan's (1984) race model, at each stop signal delay, signal respond trials are those in which the GO process is fast enough to escape inhibition. Therefore, the proportion of signal respond trials should correspond to the proportion of no stop signal trials with RT $<$ stop signal delay + SSRT. Figure 6 displays the scatterplot of hand versus eye RTs from one subject in the blocked eye + hand condition; a representative stop signal delay and the intervals exceeding that stop signal delay + SSRT are highlighted. According to the race model, the proportion of trials in which an eye and hand movement would be produced in spite of the stop signal is given by the fraction of trials with $\left[\mathrm{RT}_{\text {eye }}<\mathrm{SSD}+\mathrm{SSRT}_{\text {eye }}\right]$ and $\left[\mathrm{RT}_{\text {hand }}<\mathrm{SSD}+\mathrm{SSRT}_{\text {hand }}\right]$, where $\mathrm{RT}_{\text {eye }}, \mathrm{RT}_{\text {hand }}, \mathrm{SSRT}_{\text {eye }}$, and SSRT ${ }_{\text {hand }}$ are the RTs and the SSRTs for the eye and hand, respectively. Similarly, the proportion of eye but not hand signal respond trials corresponds to the fraction of trials with $\left[\mathrm{RT}_{\text {eye }}<\mathrm{SSD}+\mathrm{SSRT}_{\text {eye }}\right]$ and $\left[\mathrm{RT}_{\text {hand }}>\mathrm{SSD}+\right.$ $\mathrm{SSRT}_{\text {hand }}$. Likewise, the proportion of hand but not eye signal respond trials corresponds to the fraction with $\left[\mathrm{RT}_{\text {eye }}>\right.$

Table 5

Correlations of Eye and Hand Movements on No Stop Signal Trials in the Blocked and Interleaved Eye + Hand Condition and Percentages of Trials on Which the Eyes Were Faster Than $\left(\mathbf{R T}_{\text {eye }}<\mathbf{R T} \mathrm{T}_{\text {hand }}\right)$, Slower Than, or Equal To $\left(\mathrm{RT}_{\text {eye }} \geqslant \mathbf{R T} \mathrm{T}_{\text {hand }}\right)$ the Hand Movement in Experiment 1

\begin{tabular}{|c|c|c|c|c|c|c|}
\hline \multirow[b]{2}{*}{ Subject } & \multicolumn{3}{|c|}{ Blocked Condition } & \multicolumn{3}{|c|}{ Interleaved Condition } \\
\hline & $r^{2}$ & $\begin{array}{c}\% \\
\text { Eye } \\
\text { Faster }\end{array}$ & $\begin{array}{c}\% \\
\text { Eye } \\
\text { Slower }\end{array}$ & $r^{2}$ & $\begin{array}{c}\% \\
\text { Eye } \\
\text { Faster }\end{array}$ & $\begin{array}{c}\% \\
\text { Eye } \\
\text { Slower }\end{array}$ \\
\hline S.N. & .34 & 93 & 7 & .30 & 93 & 7 \\
\hline J.B. & .34 & 98 & 2 & .16 & 97 & 3 \\
\hline K.W & .48 & 100 & 0 & .52 & 100 & 0 \\
\hline E.F. & .43 & 100 & 0 & .41 & 100 & 0 \\
\hline E.L. & .56 & 67 & 33 & .57 & 56 & 44 \\
\hline
\end{tabular}

Note-All $p \mathrm{~s}<.01$. 


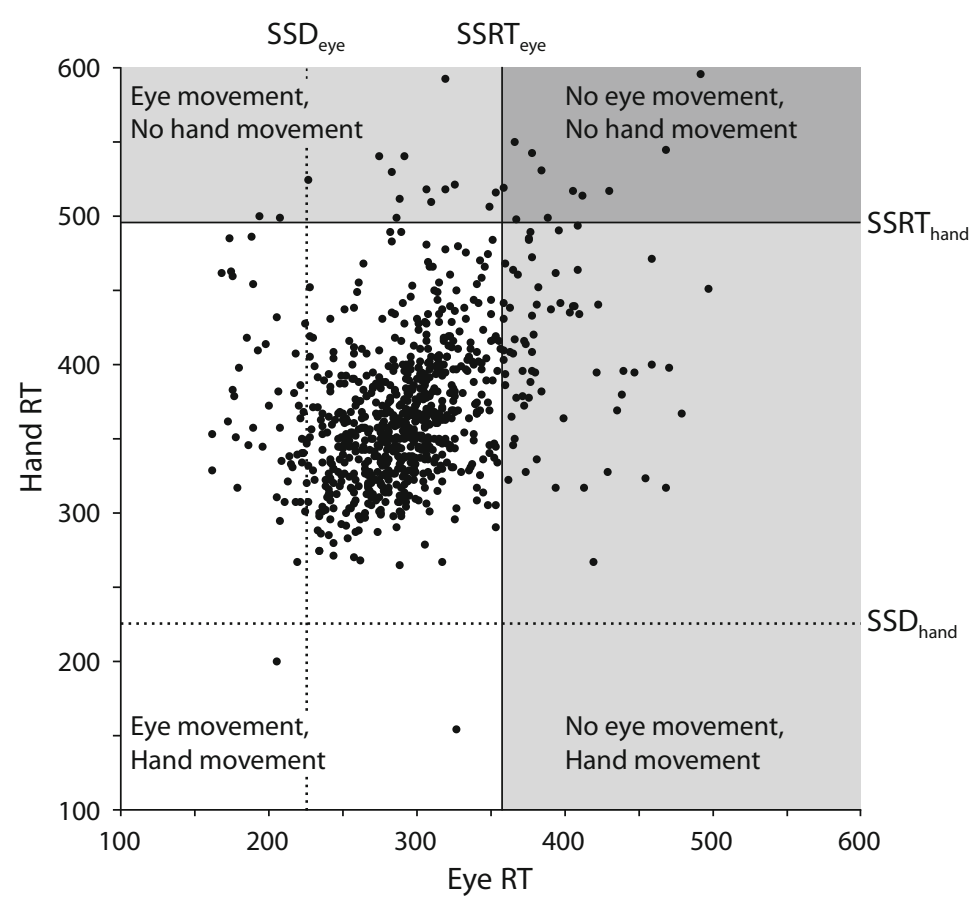

Figure 6. Eye versus hand no stop signal RTs plotted from subject $\mathrm{SN}$ in the blocked condition with a visual stop signal (Experiment 1). The stop signal delay of $225 \mathrm{msec}$ is plotted on both axes (dotted lines). The stop signal delay + SSRT for the eye $(130 \mathrm{msec})$ is plotted on the abscissa at $355 \mathrm{msec}$; the stop signal delay + SSRT for the hand $(270 \mathrm{msec})$ is plotted on the ordinate at $495 \mathrm{msec}$ (solid lines). According to the race model, SSRT divides the plot into four sections classifying each trial as one in which an eye and hand movement occurred (lower left), an eye but no hand movement occurred (upper left), a hand but no eye movement occurred (lower right), or neither an eye nor hand movement occurred (upper right) had the stop signal occurred. One can calculate the mean RT and the proportion of trials falling into each section that are the values predicted by the race model.

$\left.\mathrm{SSD}+\mathrm{SSRT}_{\text {eye }}\right]$ and $\left[\mathrm{RT}_{\text {hand }}<\mathrm{SSD}+\mathrm{SSRT}_{\text {hand }}\right]$. Finally, the predicted proportion of trials in which neither an eye or hand movement is generated corresponds to the fraction of trials with $\left[\mathrm{RT}_{\text {eye }}>\mathrm{SSD}+\mathrm{SSRT}_{\text {eye }}\right]$ and $\left[\mathrm{RT}_{\text {hand }}>\mathrm{SSD}+\right.$ $\left.\mathrm{SSRT}_{\text {hand }}\right]$. Thus, the stop signal delay + SSRT for eye and hand divides the plot into four sections in which calculations of the proportion of trials can be made for each stop signal delay. Evidence for independence between effectors will be an agreement between these predicted and observed proportions of signal respond trials in the blocked and interleaved eye + hand conditions.

Figure 7 compares the predicted with the observed proportions from the blocked eye + hand condition and the interleaved eye + hand condition with the eye, hand, or eye + hand stop signal. The observed data are indistinguishable from the predictions of the race model. The summed squared error between the predicted and observed proportions ranged between .03 and $.20($ mean $=.10)$.

The RTs of signal respond trials provide further evidence addressing the interaction between the GO and STOP processes for eye and hand movements. Figure 8 compares the predicted with the observed RTs of signal respond trials from the blocked eye + hand condition and the interleaved eye + hand condition with the eye, hand, or eye + hand stop signal. Note that the predicted mean RTs are the same for all three stop signal types in the interleaved condition as the predicted RTs are derived from the no stop signal data in that condition. The mean observed RT is plotted only if more than 20 RTs across all subjects contributed to that mean. Note that very few eye only or hand only movements are made in the interleaved condition. When subjects made a movement in spite of the stop signal, it was most often a coordinated eye + hand movement. The observed data are predicted well by the race model except at the shorter stop signal delays at which there is the least data. This can be seen by the overlap between the open circles depicting the predicted RT and the error bars (standard error of the mean across subjects) of the observed mean RT. Curiously, the few signal respond trials observed at the shortest stop signal delays had longer than expected RTs. Although some have interpreted this as a violation of the race model (e.g., Colonius, 1990; Özyurt, Colonius, \& Arndt, 2003), an alternative interpretation is that these longer than expected RTs constitute self-generated movements produced after the initial movement was inhibited. 


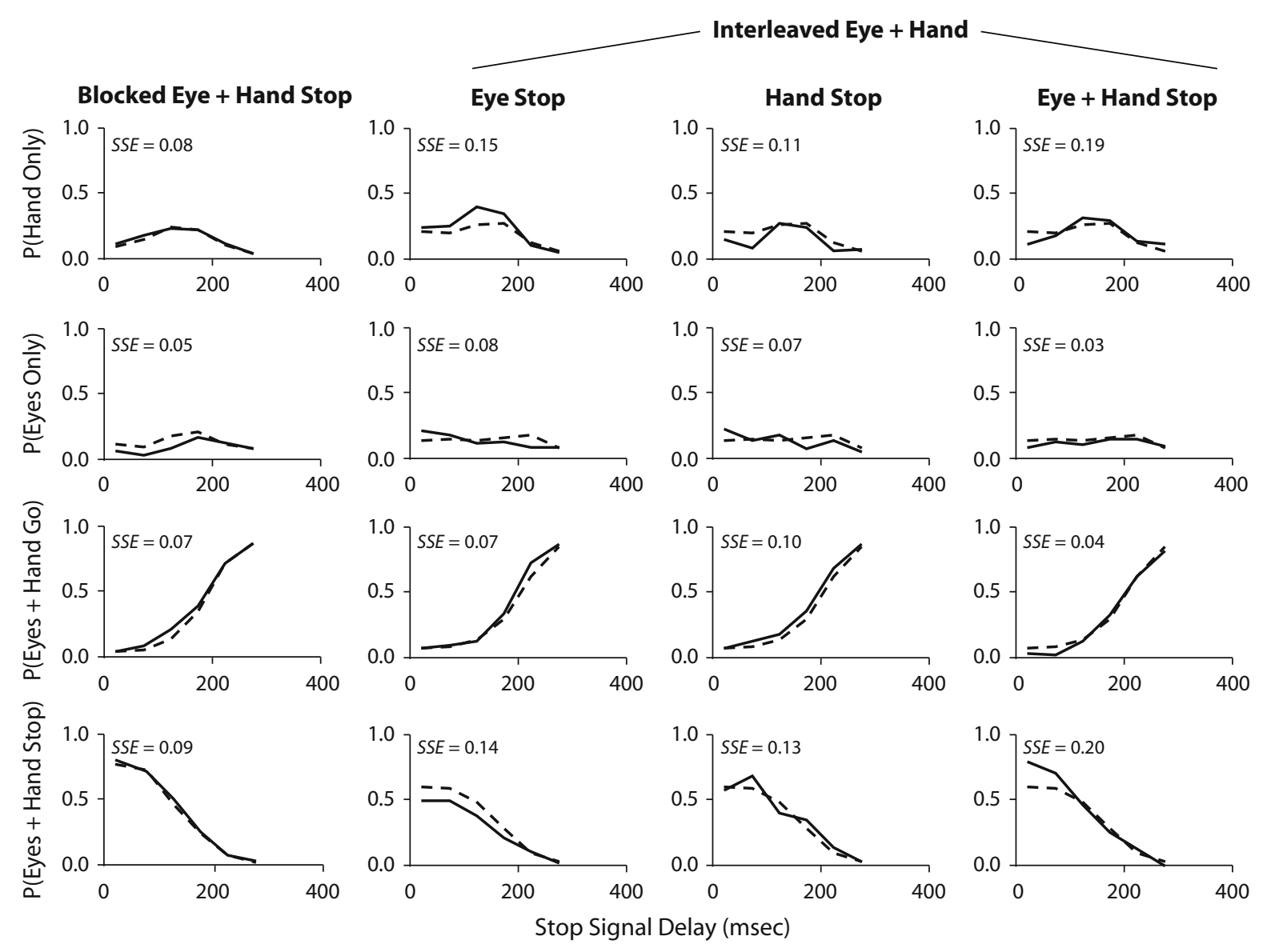

Figure 7. The proportion of trials observed (solid line) and predicted (dashed line) from the race model for each stop signal delay in which subjects moved their hand but inhibited their eye movement (top row), moved their eyes but inhibited their hand movement (second row), moved both their eyes and hand (third row), and inhibited both their eye movement and hand movement (bottom row) with a foveal visual stop signal (Experiment 1). The leftmost column is the blocked eye + hand conditions. The right three columns are the interleaved eye + hand condition with eye only, hand only, or eye + hand stop signals. Sum squared errors $(S S E)$ between the predicted and observed proportions are given.

\section{Experiment 2: Auditory Stop Signal}

The results from Experiment 1 demonstrate that knowing in advance which effector to inhibit does not confer any advantage to the subject in inhibiting a previously planned movement. Furthermore, while the GO processes for the eyes and hands are coordinated to some extent, the STOP processes for each effector were independent of one another. One possible concern with the first experiment is that the use of a visual stop signal may have bestowed an advantage on inhibiting eye movements compared to hand movements. It is known that the removal of a foveal visual stimulus facilitates the initiation of saccadic eye movements (Klein, Taylor, \& Kingstone, 1995; Reuter-Lorenz, Hughes, \& Fendrich, 1991; Ross \& Ross, 1980, 1981; Tam \& Stelmach, 1993). No such facilitation is present for hand movements. In that case, the advantage in stopping the eyes compared to the hands that we observed would not be a general phenomenon. Therefore, the second experiment used an auditory stop signal that would confer no modalityspecific advantage to either the eyes or the hands.

Mirroring our use of visual stop signals varying in color in Experiment 1, the auditory stop signal varied in tone to indicate to the subject whether they had to inhibit their eye movement, hand movement, or combined eye + hand movement. Trials were once again blocked such that subjects either knew or did not know in advance which effector to inhibit. We performed the same analyses in this experiment as in the previous experiment to establish whether a modality-neutral auditory stop signal had the same effects on stopping as our visual stop signal when effector uncertainty was manipulated.

No stop signal performance. The saccadic and manual RTs produced on no stop signal trials in all conditions are shown in Figure 9 combined across subjects; individual subject RTs are given in Table 6 . We performed a 2 (effector: eye, hand) $\times 3$ (condition: alone, blocked, interleaved) ANOVA on the mean RTs. Once again, saccades had shorter RTs than hand movements $[F(1,2)=183.71$, $\left.M S_{\mathrm{e}}=1.3 \times 10^{5}, p<.01\right]$. However, unlike Experiment 1 , the main effect of condition $\left[F(2,4)=0.37, M S_{\mathrm{e}}=\right.$ $111.56, p=.71]$, and the interaction between effector and condition $\left[F(2,4)=1.46, M S_{\mathrm{e}}=270.97, p=.34\right]$ failed to reach significance. Thus for this experiment, the RT of responses did not depend on whether the response was 
made with one or two effectors or whether subjects knew in advance which effector to inhibit.

Stop signal performance. Figure 10 plots the probability of failing to cancel a movement as a function of stop signal delay, the inhibition function, for all subjects for each stopping condition; Tables 7 and 8 provide values for individual subjects for saccadic and manual performance, respectively. We performed a 2 (effector) $\times 3$ (condition: alone, blocked, interleaved) $\times 6$ (stop signal delay) ANOVA on the inhibition functions. Once again we find an increase in the probability of signal respond trials with longer stop signal delays $\left[F(5,10)=26.33, M S_{\mathrm{e}}=0.99\right.$, $p<.01]$. There was a main effect of effector $[F(1,2)=$ $33.25, M S_{\mathrm{e}}=2.13, p=.03$ ] such that hand movements were more likely to be inhibited than eye movements in response to an auditory stop signal. This is illustrated in Figure 11 which plots the proportion of signal respond trials for eye versus hand movements with stop signal delay implied. In every condition, the data lie below the 1:1 line indicating that more hand movements were inhibited at each stop signal delay. Further, the two-way interaction between effector and condition was marginally significant $\left[F(2,4)=6.80, M S_{\mathrm{e}}=0.05, p=.05\right]$ indicating that the discrepancy in stopping (plotted as the distance from the 1:1 line) between the eyes and hands depended on whether the subject moved one or two effectors and whether they knew in advance which effector to inhibit. The main effect of condition $\left[F(2,4)=0.47, M S_{\mathrm{e}}=0.02, p=.65\right]$, the remaining two-way interactions [effector $\times \operatorname{SSD}, F(5,10)=$ $1.89, M S_{\mathrm{e}}=0.01, p=.18 ;$ condition $\times \operatorname{SSD}, F(10,20)=$ $\left.1.56, M S_{\mathrm{e}}=1.56, p=.19\right]$, and the three-way interaction [effector $\times$ condition $\times$ SSD: $F(10,20)=0.72, M S_{\mathrm{e}}=$ $\left.1.35 \times 10^{-3}, p=.70\right]$ failed to reach significance.

Stop signal reaction time. The SSRT for each condition and each effector was calculated and is shown in Table 9 for all subjects. We performed a 2 (effector) $\times 3$ (condition: alone, blocked, interleaved) ANOVA on the SSRTs. In response to the auditory stop signal, SSRT for eye movements was shorter than that for hand movements by about $100 \mathrm{msec}\left[F(1,2)=79.28, M S_{\mathrm{e}}=5.86 \times 10^{4}\right.$, $p=.01]$. This difference in SSRTs for the eyes and hands was slightly smaller than the $150 \mathrm{msec}$ difference obtained for the eyes and hands when a foveal stop signal was presented. Notably, uncertainty about which effector to cancel had no significant effect on SSRT $\left[F(2,4)=4.66, M S_{\mathrm{e}}=\right.$ $993.61, p=.09]$. There was no significant interaction of

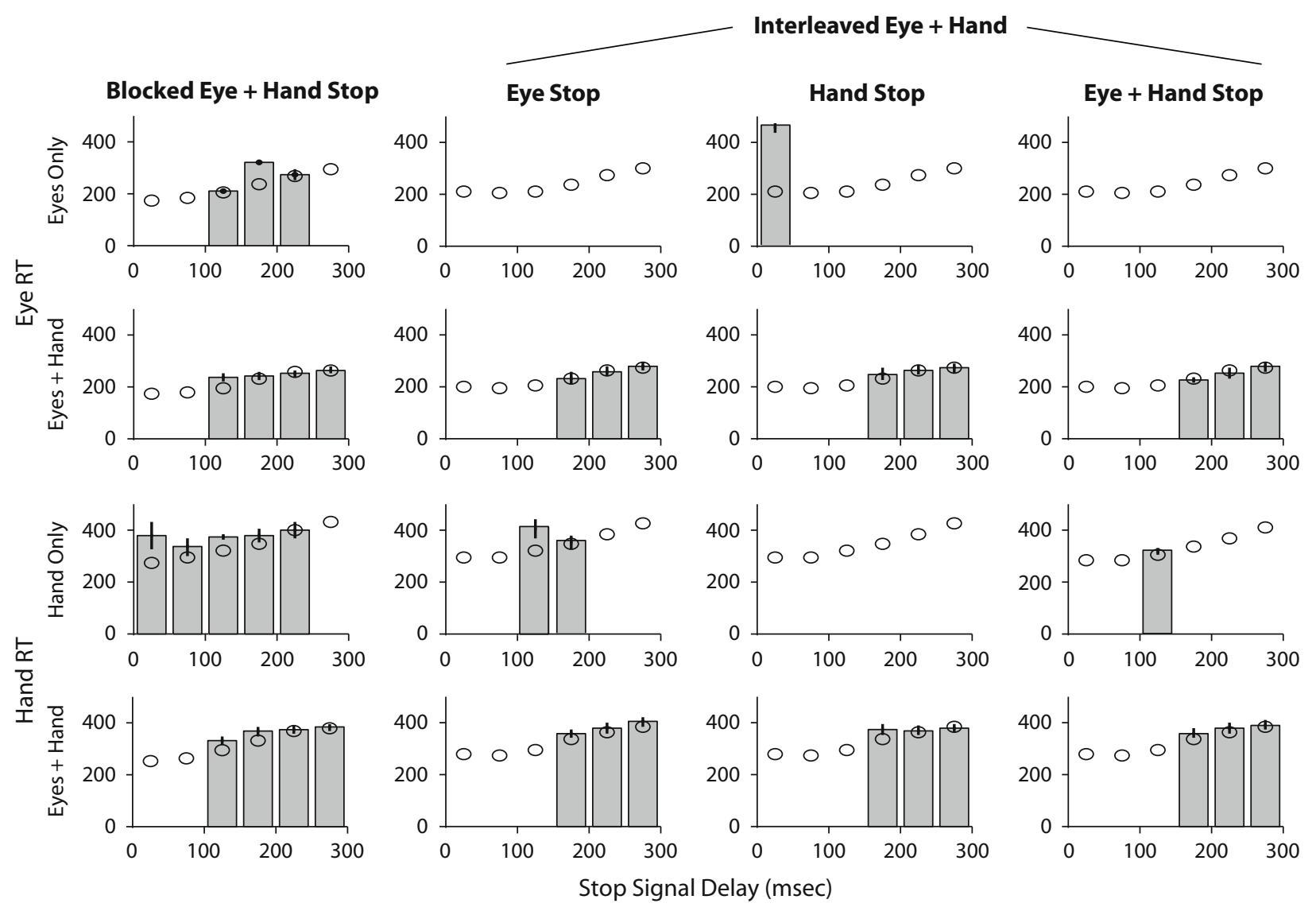

Figure 8. Mean signal respond RTs observed (solid bars) and predicted (open circles) by the race model for each stop signal delay with a foveal visual stop signal (Experiment 1). Observed data with fewer than 20 RTs across all subjects is not shown. Top row is eye RT when only the eye moved. Second row is the eye RT when both the eye and hand moved. Third row is hand RT when only the hand moved. Bottom row is hand RT when both the eye and hand moved. The first leftmost is the blocked eye + hand conditions. The right three columns are the interleaved eye + hand condition with eye only, hand only, or eye + hand stop signals. 


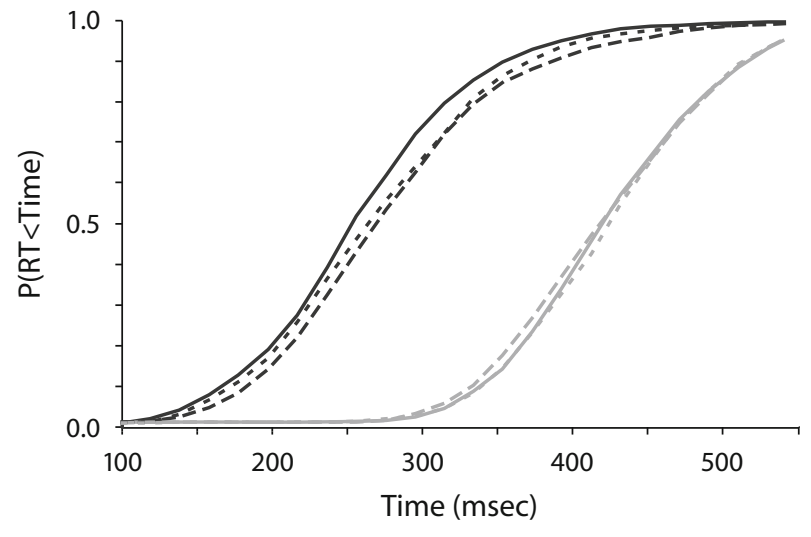

Figure 9. Cumulative distributions of reaction times on no stop signal trials for eye (black) and hand (gray) movements in the eye or hand only (solid line), blocked eye + hand (dashed line), or interleaved eye + hand (dotted line) conditions with an auditory stop signal (Experiment 2).

effector and condition $\left[F(2,4)=1.85, M S_{\mathrm{e}}=691.01, p=\right.$ .27]. Thus, as with a visual stop signal, it took longer to inhibit a hand movement in response to an auditory stop signal, but it took the same amount of time to inhibit a movement whether or not subjects knew in advance which effector to inhibit.

To determine whether the STOP processes for different effectors interact using an auditory stop signal, we examined the relationship between the duration of the GO processes for the eyes and hands. Figure 12 plots eye RT versus hand RT in the blocked and interleaved conditions. As can be seen in the scatterplots, the eyes moved sooner than the hand on the majority of trials for each subject in both the blocked and interleaved eye + hand conditions. In addition, there was a significant correlation $(p \mathrm{~s}<$ .01 ) between the RTs of eye and hand movements in no stop signal trials (Table 10). The mean correlations in the blocked and interleaved eye + hand conditions were .40 and .36 , respectively.

As discussed previously, a correlation between saccade and hand RT can occur through an interaction between the effector systems or through the influence of some other factor, such as arousal, affecting the speed of each process while preserving stochastic independence. Therefore, a better way to ascertain whether the GO and STOP processes for the two effectors interact is through an analysis of how the STOP processes of the eye and hand interact with one another. In particular, does a failure to inhibit one effector oblige a failure to inhibit the other effector?
As with the visual stop signal, we calculated the expected proportion and mean RT of signal-respond trials according to Logan and Cowan's (1984) race model. Figure 13 compares the predicted with the observed proportions from the blocked eye + hand condition and the interleaved eye + hand condition with the eye, hand, or eye + hand stop signal. The observed data are effectively indistinguishable from the predictions of the race model. The sum squared error between the predicted and observed proportions ranged between 0 and .10 (mean $=.03$ ).

As a second test of the independence of the GO and STOP processes, we compared the predicted with the observed RTs of signal respond trials from the blocked eye + hand condition and the interleaved eye + hand condition with the eye, hand, or eye + hand stop signal (Figure 14). Note that the predicted mean RTs are the same for all three stop signal types in the interleaved condition as the predicted RTs are derived from the no stop signal data in that condition. The mean observed RT is plotted only if more than 20 RTs across all subjects contributed to that mean. As a result, few means can be reported in the interleaved conditions and no hand only movements were available to be analyzed in either the blocked or interleaved eye + hand conditions. Once again, when subjects made a movement in spite of the stop signal, it was most often a coordinated eye + hand movement. The observed data are predicted well by the race model at the longest stop signal delays. The few signal respond trials observed at the shortest stop signal delays had longer than expected RTs as they did in Experiment 1. We believe that this is not a true race model violation, but instead an error in which subjects moved their eyes and/or hand after they had already stopped the movement preparation in response to the stop signal.

\section{DISCUSSION}

These experiments provide new observations about the degree and nature of interaction of the eye and hand movement control systems using visual and auditory stop signals. The correlation between eye and hand RT was replicated even though the hand movement was not a complete reaching movement, as in previous studies (Biguer et al., 1982; Fischer \& Rogal, 1986; Fisk \& Goodale, 1985; Gielen et al., 1984; Gribble et al., 2002; Herman et al., 1981; Lunenburger \& Hoffmann, 2003; Lunenburger et al., 2000; Neggers \& Bekkering, 2000; Sailer et al., 2000). However, other findings indicate an independence of the processes controlling eye and hand movement in-

Table 6

Mean No Stop Signal Reaction Times (in Milliseconds) in Experiment 2

\begin{tabular}{|c|c|c|c|c|c|c|}
\hline \multirow[b]{2}{*}{ Subject } & \multicolumn{3}{|c|}{ Eye } & \multicolumn{3}{|c|}{ Hand } \\
\hline & Eye Only & $\begin{array}{c}\text { Blocked } \\
\text { Eye + Hand }\end{array}$ & $\begin{array}{c}\text { Interleaved } \\
\text { Eye }+ \text { Hand }\end{array}$ & Hand Only & $\begin{array}{c}\text { Blocked } \\
\text { Eye }+ \text { Hand }\end{array}$ & $\begin{array}{l}\text { Interleaved } \\
\text { Eye + Hand }\end{array}$ \\
\hline M.C. & 281 & 321 & 285 & 484 & 477 & 468 \\
\hline C.N. & 284 & 272 & 260 & 423 & 410 & 417 \\
\hline C.A. & 288 & 323 & 336 & 499 & 504 & 498 \\
\hline Grand mean & 284 & 305 & 294 & 469 & 463 & 461 \\
\hline
\end{tabular}



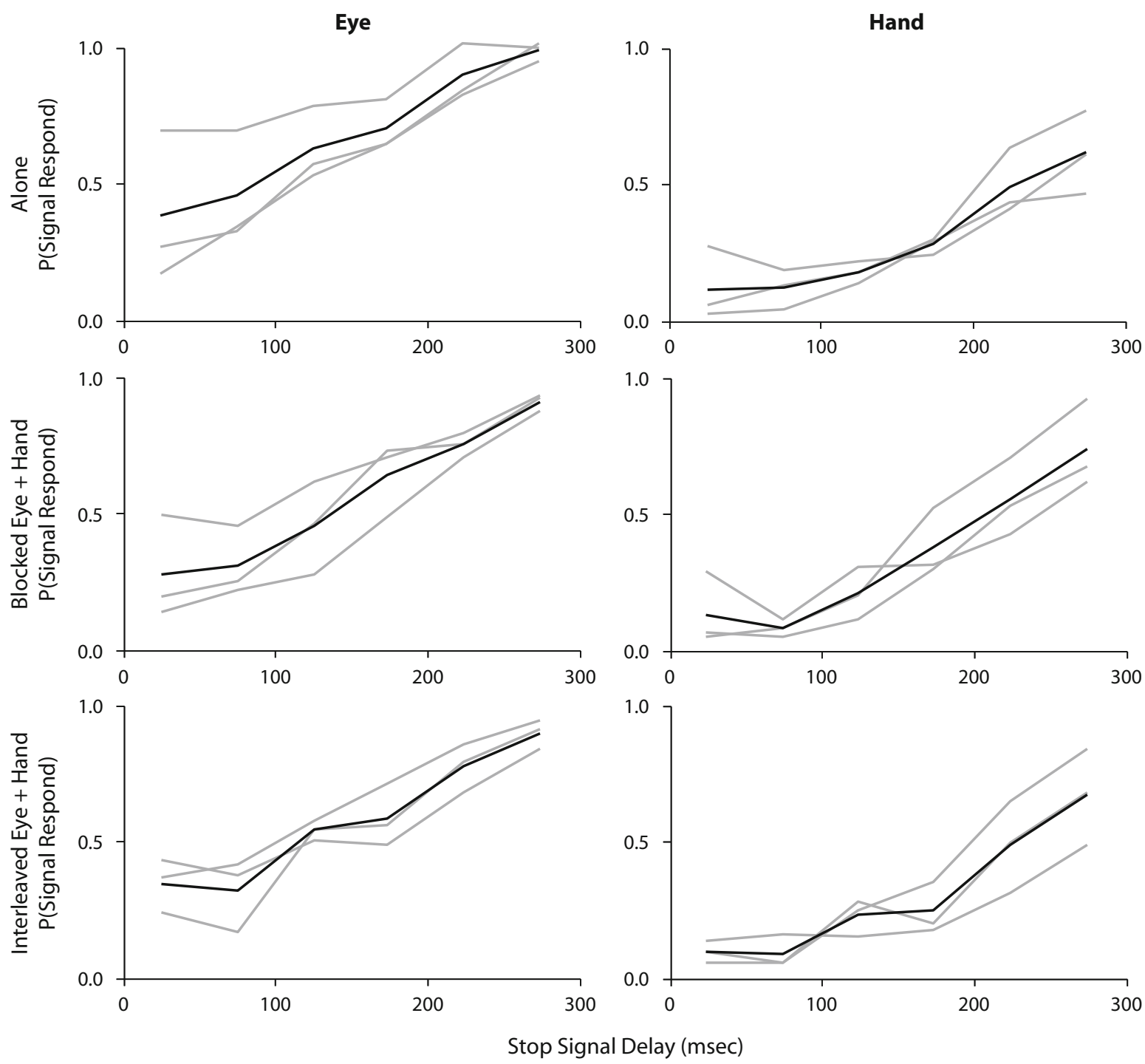

Figure 10. Proportion of signal respond trials as a function of stop signal delay with an auditory stop signal (Experiment 2). Inhibition functions for the eye and hand are in the left and right columns, respectively. Different rows display the inhibition functions in the alone (top row), blocked eye + hand (middle row), or interleaved eye + hand (bottom row) conditions. Black line is the average inhibition function across subjects (gray lines).

hibition - in particular the fact that hand movements took longer to inhibit than eye movements, and more notably, that knowing in advance which effector one had to inhibit did not confer any advantage in the time taken to inhibit either movement. Further, this advantage did not depend on the modality of the stop signal. In general, the results indicate that, in the vernacular of the race model of countermanding, eye and hand GO processes are partially correlated but at least some portion of the STOP processes for the eye and hand are not correlated with each other or with the GO processes. The STOP process is composed of peripheral and central processes (Boucher et al., 2007; DeJong et al., 1990; Logan, 1981). It is entirely possible that the central STOP process is shared between effectors with the peripheral processes being unique to each effector. We will consider this point below.

\section{Difference Between Visual and Auditory Stop Signals}

We find that the results observed with a visual stop signal were replicated with an auditory stop signal. However, we did find a difference related to the inhibition of saccades between the two stop signal modalities. There is conflicting evidence in the literature as to whether auditory stop signals yield higher or lower SSRTs for saccades as compared to those obtained with visual stop signals (e.g., Cabel, Armstrong, Reingold, \& Munoz, 2000; Colonius, Özyurt, \& Arndt, 2001; van der Schoot, Licht, Horsley, \& Sergeant, 2005). Here we find that although SSRTs were elevated for both the eyes and hands with the auditory stop signal, the difference in eye SSRT was greater. Further, the proportion of saccades that were inhibited at each stop signal delay in relation to the proportion of hand move- 
Table 7

Probability of Not Canceling an Eye Movement at Each Stop Signal Delay (SSD) in Experiment 2

\begin{tabular}{|c|c|c|c|c|c|c|}
\hline \multirow[b]{2}{*}{ Subject } & \multicolumn{6}{|c|}{ SSD } \\
\hline & 25 & 75 & 125 & 175 & 225 & 275 \\
\hline \multicolumn{7}{|c|}{ Eye-Only Condition } \\
\hline M.C. & .17 & .33 & .52 & .63 & .81 & .93 \\
\hline C.N. & .26 & .32 & .56 & .63 & .82 & 1.00 \\
\hline C.A. & .68 & .68 & .77 & .80 & 1.00 & .98 \\
\hline Grand mean & .37 & .44 & .61 & .69 & .88 & .97 \\
\hline \multicolumn{7}{|c|}{ Blocked Eye + Hand Condition } \\
\hline M.C. & .13 & .22 & .27 & .48 & .70 & .87 \\
\hline C.N. & .19 & .25 & .46 & .72 & .75 & .91 \\
\hline C.A. & .49 & .45 & .61 & .70 & .78 & .92 \\
\hline Grand mean & .27 & .30 & .44 & .63 & .74 & .90 \\
\hline \multicolumn{7}{|c|}{ Interleaved Eye + Hand Condition } \\
\hline M.C. & .22 & .15 & .53 & .55 & .78 & .90 \\
\hline C.N. & .36 & .40 & .56 & .70 & .84 & .93 \\
\hline C.A. & .42 & .36 & .49 & .48 & .67 & .83 \\
\hline Grand mean & .33 & .31 & .53 & .57 & .76 & .89 \\
\hline
\end{tabular}

Table 8

Probability of Not Canceling a Hand Movement at Each Stop Signal Delay (SSD) in Experiment 2

\begin{tabular}{lcccccc}
\hline & \multicolumn{6}{c}{ SSD } \\
\cline { 2 - 7 } \multicolumn{1}{c}{ Subject } & 25 & 75 & 125 & 175 & 225 & 275 \\
\hline \multicolumn{7}{c}{ Hand-Only Condition } \\
M.C. & .02 & .03 & .13 & .28 & .43 & .47 \\
C.N. & .05 & .12 & .18 & .30 & .63 & .77 \\
C.A. & .27 & .18 & .22 & .24 & .41 & .61 \\
Grand mean & .11 & .11 & .18 & .27 & .49 & .62 \\
\multicolumn{7}{c}{ Blocked Eye + Hand Condition } \\
M.C. & .05 & .03 & .10 & .28 & .52 & .67 \\
C.N. & .04 & .07 & .19 & .51 & .70 & .91 \\
C.A. & .27 & .10 & .29 & .30 & .41 & .61 \\
Grand mean & .12 & .07 & .20 & .36 & .54 & .73 \\
& Interleaved Eye + Hand Condition & & \\
M.C. & .05 & .05 & .28 & .20 & .50 & .68 \\
C.N. & .09 & .05 & .25 & .36 & .65 & .84 \\
C.A. & .13 & .16 & .14 & .17 & .32 & .49 \\
Grand mean & .09 & .09 & .22 & .24 & .49 & .67 \\
\hline
\end{tabular}

ments that were inhibited depended on stop signal modality. With a visual stop signal, the proportions of movements inhibited were approximately equal for the eyes and hand at each stop signal delay (Figure 4), whereas with an auditory stop signal, hand movements were inhibited more often than saccades at each stop signal delay (Figure 11). This is consistent with the potency of visual foveal stimulation on inhibiting saccadic eye movements.

Taken together, the SSRT and inhibition function results indicate that it is more difficult to inhibit an eye movement in response to an auditory stop signal than in response to a visual stop signal. This is supported by a 2 (stop signal modality: visual, auditory) $\times 2$ (effector: eye, hand) $\times 3$ (condition: alone, blocked, interleaved) $\times 6$ (stop signal delay) mixed ANOVA on the inhibition functions with modality as a between-subjects factor and the others as within-subjects factors, which revealed a sig- nificant two-way interaction between effector and stop signal modality $\left[F(1,6)=6.95, M S_{\mathrm{e}}=1.66, p=.04\right]$. Further, hand movements were not affected as strongly by the modality manipulation. Why might this be the case? Foveal visual stimuli directly map onto fixation neurons in the superior colliculus (Munoz \& Wurtz, 1993), but there is no such mapping between auditory stimuli and fixation neurons. Therefore, there may be an advantage to stopping eye movements in response to a visual stop signal, which would elevate saccade SSRT in response to an auditory stop signal. This disadvantage in stopping saccades in response to an auditory stop signal would lead to greater proportions of eye movements being produced, while not affecting the proportion of hand movements that are produced. However, it must be remembered that these results were obtained in different experiments with different subjects. An experiment specifically designed to test the efficacy of visual and auditory stop signals with eye and hand movements must be undertaken to determine if these differences in inhibiting eye and hand movements are general phenomena.

\section{Coordinated Eye and Hand Control}

Our data decisively rule out a strong interaction between the systems responsible for the canceling eye and hand movements at least under these testing conditions. If such an interaction existed, then in the blocked or interleaved eye + hand conditions we would not have observed signal respond trials in which only one of the effectors was canceled. However, we found a number of trials in which the saccade was generated but the slower hand movement could be suppressed, even in the blocked condition in which both

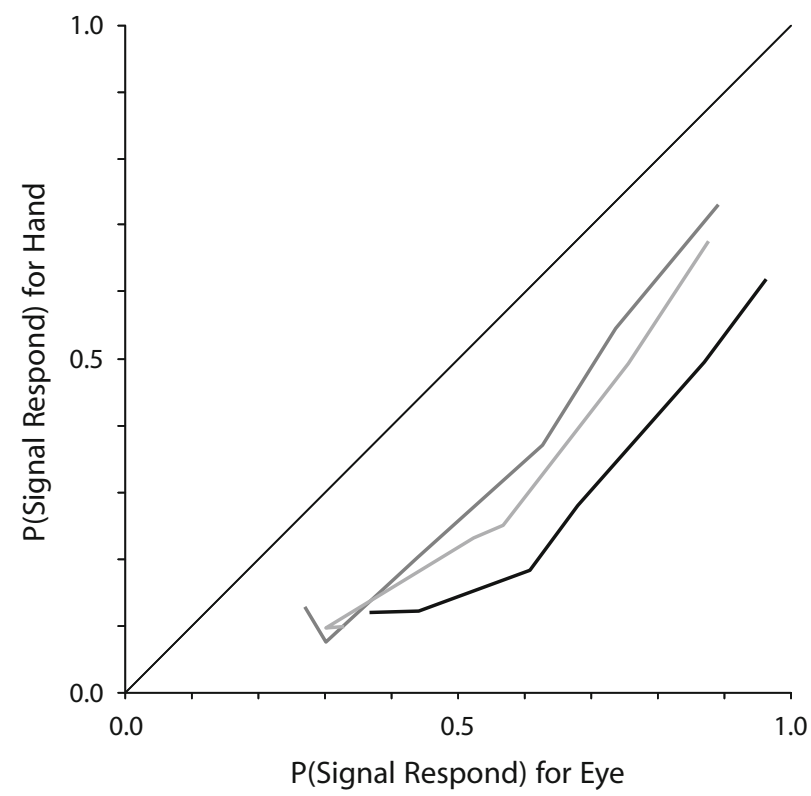

Figure 11. Proportion of signal respond trials for the eye versus the hand in the alone (black line), blocked eye + hand (dark gray line) and interleaved eye + hand (light gray line) conditions with an auditory stop signal (Experiment 2). Stop signal delay is implied. The 1:1 line is also plotted. 
Table 9

Mean Stop Signal Reaction Times (in Milliseconds) in Experiment 2

\begin{tabular}{lccccccc}
\hline & \multicolumn{3}{c}{ Eye } & & \multicolumn{3}{c}{ Hand } \\
\cline { 2 - 3 } \cline { 6 - 7 } \multicolumn{1}{c}{ Subject } & Eye Only & $\begin{array}{c}\text { Blocked } \\
\text { Eye + Hand }\end{array}$ & $\begin{array}{c}\text { Interleaved } \\
\text { Eye + Hand }\end{array}$ & & Hand Only & $\begin{array}{c}\text { Blocked } \\
\text { Eye + Hand }\end{array}$ & $\begin{array}{c}\text { Interleaved } \\
\text { Eye + Hand }\end{array}$ \\
\hline M.C. & 143 & 147 & 132 & & 288 & 279 & 275 \\
C.N. & 152 & 127 & 118 & & 236 & 239 & 237 \\
C.A. & 252 & 179 & 160 & & 292 & 305 & 287 \\
Grand mean & 182 & 151 & 137 & & 272 & 274 & 266 \\
\hline
\end{tabular}

eye and hand movements had to be suppressed. Further, this result did not depend on the modality of the stop signal.

The present data resemble in many respects those obtained in an eye-head stop signal task (Corneil \& Elsley, 2005). However, unlike the eye-hand task, in the case of eye-head gaze shifts with targets beyond the oculomotor range, Corneil and Elsley observed a significant fraction of trials in which gaze remained fixed at the central spot but the head moved toward the target. Such head movements were more common at intermediate stop signal delays. However, gaze never shifted without a head movement. These authors argued that the results can be explained if gaze shifts and head movements are controlled by a single race, preceded by terminal ballistic intervals not under inhibitory control with the head-movement branch activated at a lower threshold. Such a model may be appropriate for eye-head gaze shifts but seems implausible for eye-hand movements because the linkages are much less direct.

We found no advantage for stopping if subjects knew in advance which effector to stop or conversely, no cost if subjects were cued on each trial which effector to stop. If stopping one effector had an influence on stopping the other, then SSRT should be different when both movements are canceled as compared to when one movement was canceled. The most parsimonious explanation of this finding is that the eye and hand movements are initiated separately with some degree of correlation but inhibited through independent mechanisms.

In sum, our experiments have ruled out both a single unified control system responsible for stopping both eye and hand movement and two absolutely separated control systems without any influence from one to the other. This
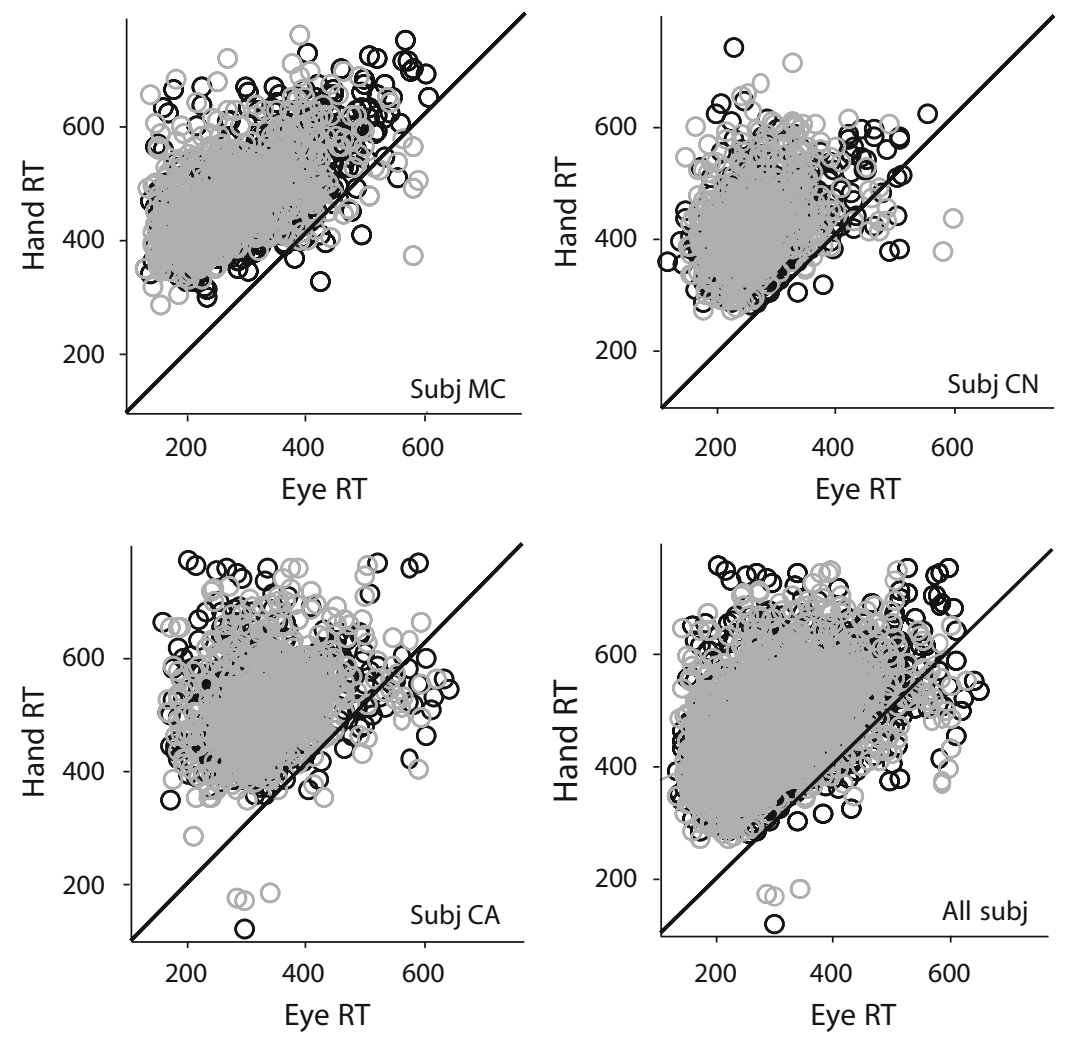

Figure 12. Eye versus hand RTs on no stop signal trials in the blocked (black) and interleaved (gray) eye + hand conditions for individual and all subjects with an auditory stop signal (Experiment 2). 
Table 10

Correlations of Eye and Hand Movements on No Stop Signal Trials in the Blocked and Interleaved Eye + Hand Condition and Percentages of Trials on Which the Eyes Were Faster Than $\left(\mathbf{R T}_{\text {eye }}<\mathbf{R T}_{\text {hand }}\right)$, Slower Than, or Equal To $\left(\mathbf{R T}_{\text {eye }}>\mathbf{R T} \mathrm{T}_{\text {hand }}\right)$ the Hand Movement in Experiment 2

\begin{tabular}{lccccccc}
\hline & \multicolumn{3}{c}{ Blocked Condition } & & \multicolumn{3}{c}{ Interleaved Condition } \\
\cline { 2 - 3 } \cline { 7 - 8 } & & $\begin{array}{c}\% \\
\text { Eye }\end{array}$ & $\begin{array}{c}\% \\
\text { Eye }\end{array}$ & & $\begin{array}{c}\% \\
\text { Eye }\end{array}$ & $\begin{array}{c}\% \\
\text { Eye } \\
\text { Subject }\end{array}$ \\
& $r^{2}$ & Faster & Slower & & $r^{2}$ & Faster & Slower \\
\hline M.C. & .62 & 99 & 1 & & .49 & 98 & 2 \\
C.N. & .41 & 98 & 2 & & .34 & 99 & 1 \\
C.A. & .17 & 96 & 4 & & .25 & 98 & 2 \\
\hline
\end{tabular}

seems to indicate two effector systems that influence each other to some degree.

\section{Difference Between Eye and Hand SSRT}

If the eye and the hand were stopped by a common system, it seems reasonable to expect an identical SSRT for the two movements. Thus, at first glance the fact that the SSRT for the hand is $100-150$ msec longer than the
SSRT for the eye seems to provide additional evidence in favor of two stopping systems. Nevertheless, we would expect to see some differences in the SSRT for eye and hand movements even in the extreme case of a single central stopping system and even more so in the less extreme case of interaction between two semiautonomous stopping systems. The reason for this is the fact that the SSRT is the sum of peripheral and central processes (Boucher et al., 2007; DeJong et al., 1990; Logan, 1981). Central processes include, but are not limited to, sensorimotor mapping processes and working memory. The peripheral processes include sensory and motor processes, both of which can cause differences in SSRT that do not reflect differences in the duration of central processes. The multistage structure of SSRT provides several hypotheses about the origin of the difference between the eye and hand SSRTs.

First, since the calculation of SSRT includes the ballistic interval preceding a movement (Logan \& Cowan, 1984), the difference in SSRT for the eye and hand may be due to differences in the ballistic delay for these effectors. The ballistic delay for the eyes is between $10-15 \mathrm{msec}$, which
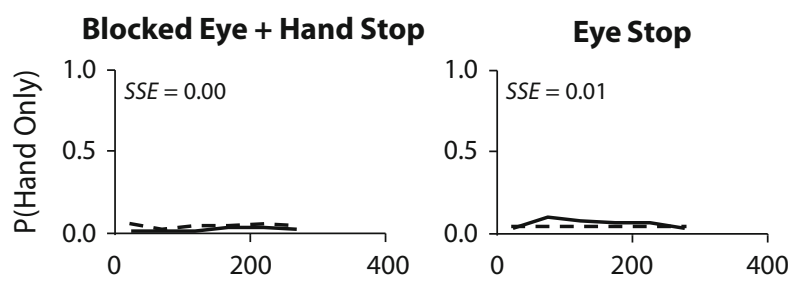

Interleaved Eye + Hand
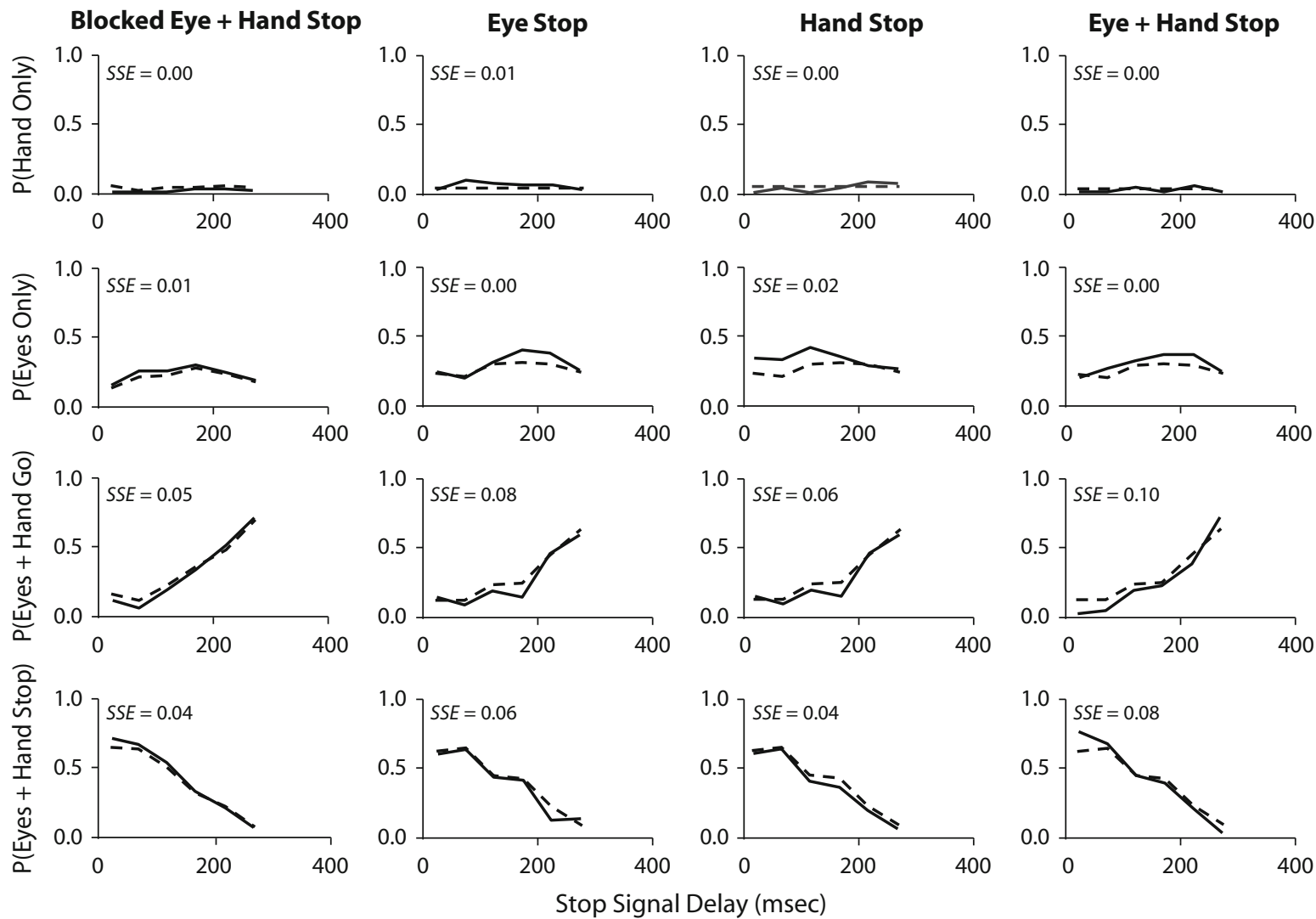

Figure 13. The proportion of trials observed (solid line) and predicted (dashed line) from the race model for each stop signal delay in which subjects moved their hand but inhibited their eye movement (top row), moved their eyes but inhibited their hand movement (second row), moved both their eyes and hand (third row), and inhibited both their eye movement and hand movement (bottom row) with an auditory stop signal (Experiment 2). The leftmost column is the blocked eye + hand conditions. The right three columns are the interleaved eye + hand condition with eye only, hand only, or eye + hand stop signals. Sum squared errors $(S S E)$ between the predicted and observed proportions are given. 


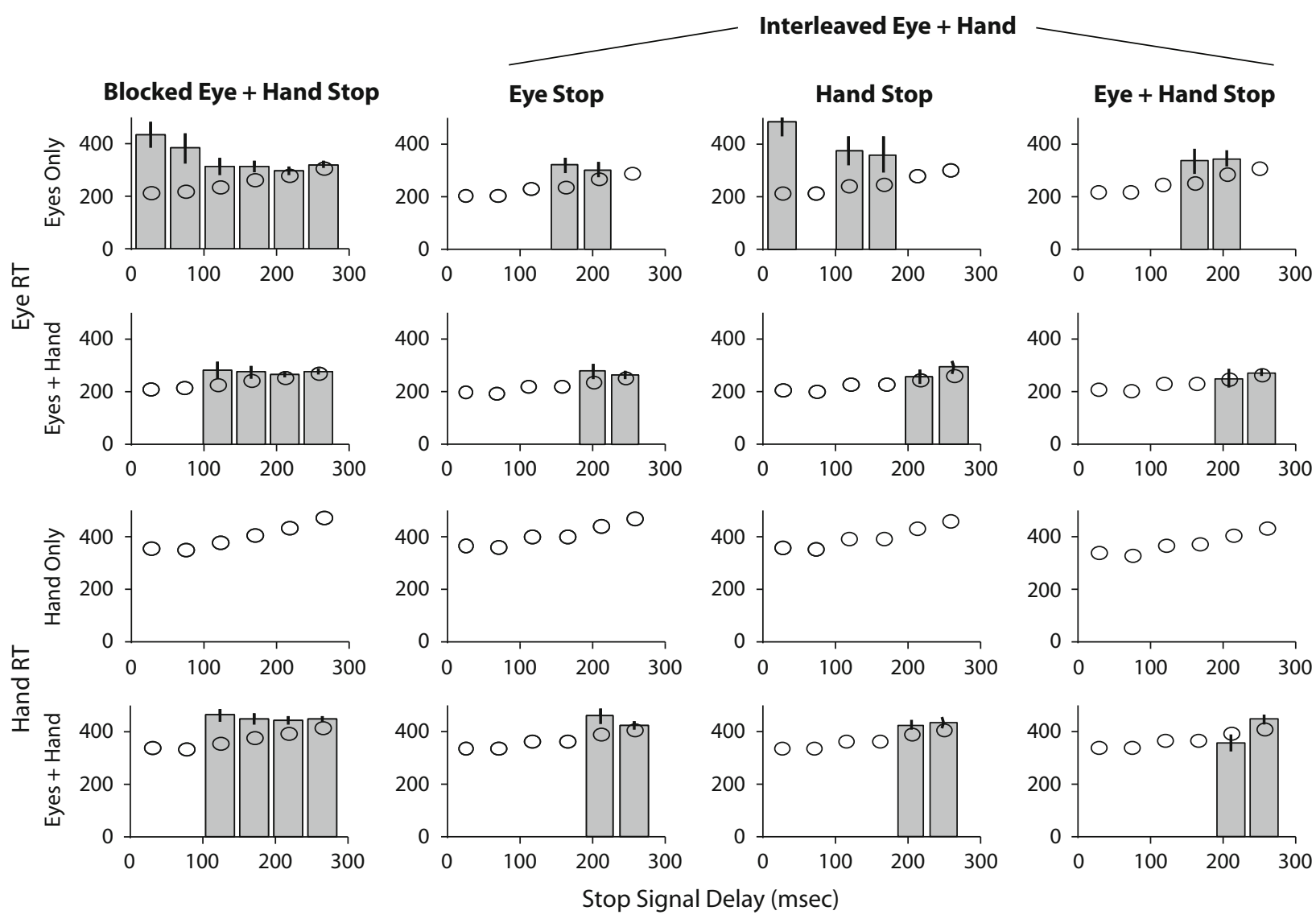

Figure 14. Mean signal respond RTs observed (solid bars) and predicted (open circles) by the race model for each stop signal delay with an auditory stop signal (Experiment 2). Observed data with fewer than 20 RTs across all subjects is not shown. Top row is eye RT when only the eye moved. Second row is the eye RT when both the eye and hand moved. Third row is hand RT when only the hand moved. Bottom row is hand $R T$ when both the eye and hand moved. The first leftmost is the blocked eye + hand conditions. The right three columns are the interleaved eye + hand condition with eye only, hand only, or eye + hand stop signals.

corresponds to the time that the omnidirectional pause neurons release their inhibition on the neurons which enervate the eye muscles (Scudder, Kaneko, \& Fuchs, 2002). Evidence for a ballistic delay for continuous movements of the hands is less clear, although stop signal studies suggest that it is after the response selection stage (Logan, 1981). In fact, hand movements can be interrupted during execution (DeJong et al., 1990). Therefore, differences in the ballistic interval between the eyes and hands are insufficient to account for the magnitude of difference in SSRT we observed for the eye and hand.

A second source of the difference in SSRT could be due to afferent delay. A foveal visual stimulus activates fixation neurons in the superior colliculus (Munoz \& Wurtz, 1993). Thus the stop signal maps directly onto gaze fixation. There is no functional reason nor any neurophysiological evidence for a similar automatic mapping in the case of forelimb restraint. Therefore, the mapping between visual stimulus and arm movement suppression is less direct and thus slower.

Finally, a third source of the difference in SSRT is a potential ambiguity in the mapping between the hand stop signal and the appropriate motor response, which does not exist for eye movements with foveal stop signals. One can stop a joystick movement in many different ways (e.g., by not moving the hand, by contracting antagonist and agonistic muscles, or by releasing the joystick). This choice may unfold over time. For example, if arm muscles are already activated to move the joystick, counteracting antagonistic muscles would need to be activated to stop the arm movement. If no muscles have been activated yet, stopping simply entails not activating anything. Stopping the eyes entails simply maintaining fixation, but stopping the hands entails choosing among the different ways in which the movement can be stopped, and greater degrees of choice are associated with longer RTs, at least for hand movements (Hick, 1952; Hyman, 1953; Kveraga, Boucher, \& Hughes, 2002). In this sense, then, stopping the eyes may be easier than stopping the hand.

\section{Race Model Violations}

Overall, the proportion and latency of signal respond trials corresponded well to the predictions of the race model. However, the mean RT of the few signal respond trials 
observed at the shortest stop signal delays were longer than predicted by the race model. This has been observed before (e.g., Logan \& Cowan, 1984) and some researchers have suggested that these longer RTs at short stop signal delays provide evidence for interaction between the GO and STOP processes which violates the premise of the race model (e.g., Colonius, 1990; Özyurt et al., 2003). However, we suggest that the long RTs can be classified as "noncompliant" errors as opposed to errors of inhibition. Consider that the mean signal respond RTs at the shortest stop signal delays are substantially longer than the time needed to cancel the movement (stop signal delay + SSRT). For example, SSRT as calculated for saccades in the interleaved condition in Experiment 1 is equal to $110 \mathrm{msec}$, yet the mean signal respond RT with the hand stop signal at a stop signal delay of $25 \mathrm{msec}$ is $453 \mathrm{msec}$. In other words, $343 \mathrm{msec}$ after the eye movement is canceled (stop signal delay + SSRT $=135 \mathrm{msec}$ ), a saccade is made. Thus, subjects may not have failed to inhibit the movement. Instead, it is more likely that subjects first cancel the movement but subsequently make the movement in spite of previously stopping. According to this argument, these longer than expected RTs need not be construed as evidence for interaction between the GO and STOP processes, but rather as the result of subjects' impatience in maintaining fixation for the duration of the trial.

\section{AUTHOR NOTE}

We thank Alex Gotler and Kate Reis for assistance with manuscript preparation. This work was supported by Robin and Richard Patton through the E. Bronson Ingram Chair in Neuroscience and grants NSF BCS0218507, F32-EY016679, RO1-MH55806, P30-EY08126 and P30-HD015052. Preliminary results have appeared in abstract form (Boucher, Stuphorn, Logan, Palmeri, \& Schall, 2004). Correspondence concerning this article should be addressed to G. D. Logan, Department of Psychology, Vanderbilt University, 301 Wilson Hall, 111 21st Avenue South, Nashville, TN 37203 (e-mail: gordon.logan@vanderbilt.edu).

\section{REFERENCES}

Band, G. P. H., van der Molen, M. W., \& Logan, G. D. (2003). Horserace model simulations of the stop-signal procedure. Acta Psychologica, 112, 105-142.

Biguer B., Jeannerod, M., Prablanc, C. (1982). The coordination of eye, head, and arm movements during reaching at a single visual target. Experimental Brain Research, 46, 301-304.

Boucher, L., Logan, G. D., PAlmeri, T. J., Schall, J.D. (2007). Interactive race model of countermanding saccades. Psychological Review.

Boucher, L., Stuphorn, V., Logan, G. D., Palmeri, T. J., Schall, J. D. (2004). Dissecting the stop process: Eye-hand coordination in a stop task (Program No. 313.6. Abstract Viewer/Itinerary Planner). Washington, DC: Society for Neuroscience.

Cabel, D. W., Armstrong, I. T., Reingold, E., \& Munoz, D. P. (2000). Control of saccade initiation in a countermanding task using visual and auditory stop signals. Experimental Brain Research, 133, 431-441.

Colonius, H. (1990). A note on the stop-signal paradigm, or How to observe the unobservable. Psychological Review, 97, 309-312.

Colonius, H., Özyurt. J., \& Arndt, P. A. (2001). Countermanding saccades with auditory stop signals: testing the race model. Vision Research, 41, 1951-1968.

CorneIL, B. D., \& ElsLey, J. K. (2005). Countermanding eye-head gaze shifts in humans: marching orders are delivered to the head first. Journal of Neurophysiology, 94, 883-895.

De Jong, R., Coles, M.G. H., Logan, G. D., \& Gratton, G. (1990). In search of the point of no return: The control of response processes.
Journal of Experimental Psychology: Human Perception \& Performance, 16, 164-182.

Fischer, B., \& Rogal, L. (1986). Eye-hand-coordination in man: a reaction time study. Biological Cybernetics, 55, 253-261.

FISK, J. D., \& Goodale, M. A. (1985). The organization of eye and limb movements during unrestricted reaching to targets in contralateral and ipsilateral visual space. Experimental Brain Research, 60, 159-78.

Gielen, C. C. A. M., van den Heuvel, P. J. M, \& van Gisbergen, J. A. M. (1984). Coordination of fast eye and arm movements in a tracking task. Experimental Brain Research, 56, 154-161.

Gribble, P. L., Everling, S., Ford, K., \& Mattar, A. (2002). Handeye coordination for rapid pointing movements. Arm movement direction and distance are specified prior to saccade onset. Experimental Brain Research, 145, 372-82.

HANES, D. P., \& CARPENTER, R. H. S. (1995). Countermanding saccades in humans. Vision Research, 39, 2777-2791.

HaNes, D.P., \& SCHALL, J.D. (1995). Countermanding saccades in macaques. Visual Neuroscience, 12, 929-937.

Herman, R., Herman, R., \& Maulucci, R. (1981). Visually triggered eyearm movements in man. Experimental Brain Research, 42, 392-398.

HicK, W. E. (1952). On the rate of gain of information. Quarterly Journal of Experimental Psychology, 4, 11-26.

Hodgson, T. L., Muller, H. J., O’Leary, M. J. (1995). Attentional localization prior to simple and directed manual responses. Perception \& Psychophysics, 61, 308-321.

Hyman, R. (1953). Stimulus information as a determinant of reaction time. Journal of Experimental Psychology, 45, 188-196.

Kveraga, K. V., Boucher, L., \& Hughes, H. C. (2002). Saccades operate in violation of Hick's Law. Experimental Brain Research, 146, 307-314.

Klein, R. M., Taylor, T. L., \& Kingstone, A. (1995). Against a role for attentional disengagement in the gap effect: a friendly amendment to Tam and Stelmach (1993). Perception \& Psychophysics, 57, 573-577.

LAPPIN, J. S., \& ERIKSEN, C. W. (1966). Use of a delayed signal to stop a visual reaction-time response. Journal of Experimental Psychology, 72, 803-811.

LogAN, G. D. (1981). Attention, automaticity, and the ability to stop a speeded choice response. In J. [B.] Long \& A. [D.] Baddeley (Eds.), Attention and performance IX (pp. 205-222). Hillsdale, NJ: Erlbaum.

Logan, G. D. (1994). On the ability to inhibit thought and action: A users' guide to the stop signal paradigm. In D. Dagenbach \& T. H. Carr (Eds), Inhibitory processes in attention, memory, and language (pp. 189-239). San Diego: Academic Press.

Logan, G. D., \& CowAn, W. B. (1984). On the ability to inhibit thought and action: A theory of an act of control. Psychological Review, 91, 295-327.

Logan, G. D., \& Irwin, D. E. (2000). Don't look! Don't touch! Inhibitory control of eye and hand movements. Psychonomic Bulletin \& Review, 7, 107-112.

Lunenburger, L., \& Hoffmann, K. P. (2003). Arm movement and gap as factors influencing the reaction time of the second saccade in a double-step task. European Journal of Neuroscience, 17, 2481-2491.

Lunenburger, L., Kutz, D. F., \& Hoffmann, K. P. (2000). Influence of arm movements on saccades in humans. European Journal of Neuroscience, 12, 4107-4116.

Munoz, D. P., \& Wurtz, R. (1993). Fixation cells in monkey superior colliculus. I. Characteristics of cell discharge. Journal of Neurophysiology, 70, 559-575.

NegGeRS, S. F., \& BEKKERING, H. (2000). Ocular gaze is anchored to the target of an ongoing pointing movement. Journal of Neurophysiology, 83, 639-651.

Özyurt, J., Colonius, H., Arndt, P. A. (2003) Countermanding saccades: evidence against independent processing of go and stop signals. Perception \& Psychophysics, 65, 420-428.

Reuter-Lorenz, P. A., Hughes, H. C., \& Fendrich R. (1991). The reduction of saccadic latency by prior offset of the fixation point: an analysis of the gap effect. Perception \& Psychophysics, 49, 167-175.

Ross, L. E., \& Ross, S. M. (1980). Saccade latency and warning signals: stimulus onset, offset, and change as warning events. Perception \& Psychophysics, 27, 251-257.

Ross, L. E., \& Ross, S. M. (1981). Saccade latency and warning signals: 
effects of auditory and visual stimulus onset and offset. Perception \& Psychophysics, 29, 429-423.

Sailer, U., Eggert, T., Ditterich, J., \& Straube, A. (2000). Spatial and temporal aspects of eye-hand coordination across different tasks. Experimental Brain Research, 134, 163-73.

Scudder, C. A., Kaneko, C. S., \& Fuchs, A. F. (2002). The brainstem burst generator for saccadic eye movements: A modern synthesis. Experimental Brain Research, 142, 439-462.

SNYDER, L. H. (2000). Coordinate transformations for eye and arm movements in the brain. Current Opinion in Neurobiology, 10, 747-54.

Snyder, L. H., Calton, J. L., Dickinson, A. R., \& Lawrence, B. M. (2002). Eye-hand coordination: saccades are faster when accompanied by a coordinated arm movement. Journal of Neurophysiology, 87, 2279-2286.

Stuphorn, V., Hoffmann, K. P., \& Miller, L. E. (1999). Correlation of primate superior colliculus and reticular formation discharge with proximal limb muscle activity. Journal of Neurophysiology, 81, 1978-1982.
Tam, W. J., \& Stelmach, L. B. (1993). Viewing behavior: ocular and attentional disengagement. Perception \& Psychophysics, 54, 211-222

Tipper, S. P., Howard, L. A., \& Paul, M. A. (2001). Reaching affects saccade trajectories. Experimental Brain Research, 136, 241-249.

van der Schoot, M., Licht, R., Horsley, T. M., \& Sergeant, J. A. (2005). Effects of stop signal modality, stop signal intensity and tracking method on inhibitory performance as determined by use of the stop signal paradigm. Scandinavian Journal of Psychology, 46, 331-341

van Donkelaar, P., Siu, K. C., Walterschied, J. (2004). Saccadic output is influenced by limb kinetics during eye-hand coordination. Journal of Motor Behavior, 36, 245-252.

(Manuscript received September 9, 2005;

revision accepted for publication December 4, 2006.) 